Review

\title{
Ochratoxin A: General Overview and Actual Molecular Status
}

\section{André el Khoury ${ }^{1}$ and Ali Atoui ${ }^{2, *}$}

1 Centre d'analyses et de recherches, Faculté des Sciences, Université Saint-Joseph, Beyrouth, Lebanon

2 Lebanese Atomic Energy Commission-CNRS, P.O. Box 11-8281, Riad El Solh, 11072260 Beirut, Lebanon

* Author to whom correspondence should be addressed; E-Mail: a.atoui@cnrs.edu.lb; Tel.: 00961 (1) 450 811; Fax: 00961 (1) 450810.

Received: 24 January 2010; in revised form: 5 March 2010 / Accepted: 8 March 2010 / Published: 29 March 2010

\begin{abstract}
Ochratoxin A (OTA) is a mycotoxin produced by several species of Aspergillus and Penicillium fungi that structurally consists of a para-chlorophenolic group containing a dihydroisocoumarin moiety that is amide-linked to L-phenylalanine. OTA is detected worldwide in various food and feed sources. Studies show that this molecule can have several toxicological effects such as nephrotoxic, hepatotoxic, neurotoxic, teratogenic and immunotoxic. A role in the etiology of Balkan endemic nephropathy and its association to urinary tract tumors has been also proved. In this review, we will explore the general aspect of OTA: physico-chemical properties, toxicological profile, OTA producing fungi, contaminated food, regulation, legislation and analytical methods. Due to lack of sufficient information related to the molecular background, this paper will discuss in detail the recent advances in molecular biology of OTA biosynthesis, based on information and on new data about identification and characterization of ochratoxin biosynthetic genes in both Penicillium and Aspergillus species. This review will also cover the development of the molecular methods for the detection and quantification of OTA producing fungi in various foodstuffs.
\end{abstract}

Keywords: Ochratoxin A; toxicity; polyketide synthase gene; molecular biology; biosynthesis; detection; quantification 


\section{Definition}

Ochratoxin A (OTA) is a mycotoxin produced by secondary metabolism of many filamentous species belonging to the genera Aspergillus and Penicillium [1-4]. Biosynthetically, it is a pentaketide derived from the dihydrocoumarins family coupled to $\beta$-phenylalanine. Its chemical name is: L-phenylalanine- $N$-[(5-chloro-3,4-dihydro-8-hydroxy-3-methyl-1-oxo-1H-2-benzopyrane-7-yl)carbonyl] $-(R)$-isocoumarin and its chemical structure is presented in Figure 1.

Figure 1. Chemical structure of ochratoxin A.

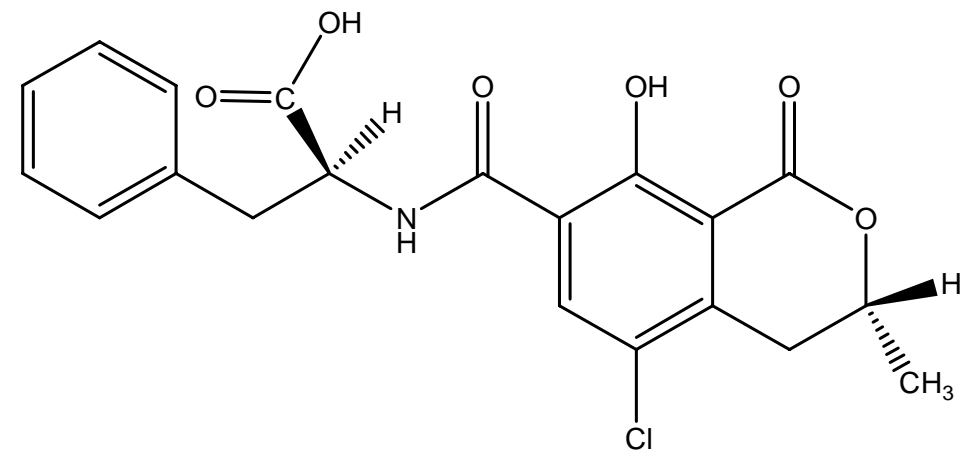

\section{Ochratoxin A Derived Metabolites}

Several metabolites related to OTA have been also identified, particularly, ochratoxin B (OTB) the dechloro analog of OTA, ochratoxin C (OTC) its ethyl ester, the isocoumaric derivative of OTA, ochratoxin $\alpha(\mathrm{Ot} \alpha)$, and its dechloro analog, ochratoxin $\beta(\mathrm{OT} \beta)$. Figure 2 presents the general structure common to these different metabolites and Table 1 shows the characteristic composition of each one. Recently, new OTA derived metabolites have been characterized, which include a dechlorinated ochratoxin A derivative identified by nono-ESI-IT-MS [5] and a quinone/hydroquinone metabolite showing toxicological properties [6]. In addition, it is predicted that OTA will form a benzoquinone electrophile following activation by cytochrome P450 enzymes, and radical species following activation by enzymes with peroxidase activities [7,8]. These electrophiles react preferentially with deoxyguanosine $(\mathrm{dG})$ to form benzetheno adducts and $\mathrm{C} 8 \mathrm{-dG}$ adducts, respectively [8].

Figure 2. General structure of ochratoxin A metabolites.<smiles>[R]C[C@@]1([2H])OC(=O)c2c(O)c(C([R])=O)cc([R])c2C1([R6])[R5]</smiles> 
Table 1. Characteristic composition of ochratoxin A derived metabolites.

\begin{tabular}{|c|c|c|c|c|c|}
\hline Name & R1 & $\mathbf{R 2}$ & R3 & R4 & R5 \\
\hline \multicolumn{6}{|l|}{ Natural ochratoxins } \\
\hline Ochratoxin A & Phenylalanine & $\mathrm{Cl}$ & $\mathrm{H}$ & $\mathrm{H}$ & $\mathrm{H}$ \\
\hline Ochratoxin B & Phenylalanine & $\mathrm{H}$ & $\mathrm{H}$ & $\mathrm{H}$ & $\mathrm{H}$ \\
\hline Ochratoxin $\mathrm{C}$ & Ethyl-ester, phenylalanine & $\mathrm{Cl}$ & $\mathrm{H}$ & $\mathrm{H}$ & $\mathrm{H}$ \\
\hline Ochratoxin A Methyl-ester & Methyl-ester, phenylalanine & $\mathrm{Cl}$ & $\mathrm{H}$ & $\mathrm{H}$ & $\mathrm{H}$ \\
\hline Ochratoxin B Methyl-ester & Methyl-ester, phenylalanine & $\mathrm{H}$ & $\mathrm{H}$ & $\mathrm{H}$ & $\mathrm{H}$ \\
\hline Ochratoxin B Ethyl-ester & Ethyl-ester, phenylalanine & $\mathrm{H}$ & $\mathrm{H}$ & $\mathrm{H}$ & $\mathrm{H}$ \\
\hline Ochratoxin $\alpha$ & $\mathrm{OH}$ & $\mathrm{Cl}$ & $\mathrm{H}$ & $\mathrm{H}$ & $\mathrm{H}$ \\
\hline Ochratoxin $\beta$ & $\mathrm{OH}$ & $\mathrm{H}$ & $\mathrm{H}$ & $\mathrm{H}$ & $\mathrm{H}$ \\
\hline 4-R-Hydroxyochratixn A & Phenylalanine & $\mathrm{Cl}$ & $\mathrm{H}$ & $\mathrm{OH}$ & $\mathrm{H}$ \\
\hline 4-s-Hydroxyochratoxin A & Phenylalanine & $\mathrm{Cl}$ & $\mathrm{OH}$ & $\mathrm{H}$ & $\mathrm{H}$ \\
\hline 10-Hydroxyochratoxin A & Phenylalanine & $\mathrm{Cl}$ & $\mathrm{H}$ & $\mathrm{H}$ & $\mathrm{OH}$ \\
\hline Tyrosine analog of OTA & Tyrosine & $\mathrm{Cl}$ & $\mathrm{H}$ & $\mathrm{H}$ & $\mathrm{H}$ \\
\hline Serine analog of OTA & Serine & $\mathrm{Cl}$ & $\mathrm{H}$ & $\mathrm{H}$ & $\mathrm{H}$ \\
\hline $\begin{array}{l}\text { Hydroxyproline analog of } \\
\text { OTA }\end{array}$ & Hydroxyproline & $\mathrm{Cl}$ & $\mathrm{H}$ & $\mathrm{H}$ & $\mathrm{H}$ \\
\hline Lysine analog of OTA & Lysine & $\mathrm{Cl}$ & $\mathrm{H}$ & $\mathrm{H}$ & $\mathrm{H}$ \\
\hline \multicolumn{6}{|l|}{ Synthetic ochratoxins } \\
\hline d-Ochratoxin A & d-phenylalanine & $\mathrm{Cl}$ & $\mathrm{H}$ & $\mathrm{H}$ & $\mathrm{H}$ \\
\hline Ochratoxin A Ethyl amid & Ethyl amid, phenylalanine & $\mathrm{Cl}$ & $\mathrm{H}$ & $\mathrm{H}$ & $\mathrm{H}$ \\
\hline O-methyl Ochratoxin A & $\begin{array}{l}\text { Phenylalanine, } \mathrm{OHCH}_{3} \text { on } \\
\text { C-8 }\end{array}$ & $\mathrm{Cl}$ & $\mathrm{H}$ & $\mathrm{H}$ & $\mathrm{H}$ \\
\hline
\end{tabular}

\section{Physico-Chemicals Properties of Ochratoxin A}

OTA is a weak organic acid with a pKa value of 7.1 [1-3] and a molar mass of 403.8 g.mol ${ }^{-1}$. With crystalline structure varying from colorless to white, this molecule posses an intense green fluorescence under UV light in acid medium and blue fluorescence in alkaline conditions [4].

In acid and neutral pH, OTA is soluble in polar organic solvents (alcohols, ketones, chloroform), slightly soluble in water and insoluble in petroleum ethers and saturated hydrocarbons. While in alkaline conditions, this molecule is soluble in aqueous sodium bicarbonate solution and in all alkaline solutions in general. It has a melting point of about $90{ }^{\circ} \mathrm{C}$ when crystallized from benzene as a solvate. However, non-solvated crystals of melting point $169^{\circ} \mathrm{C}$ have been obtained from xylene, which are suitable for X-ray structural analysis. OTA is optically active and its spectral characteristics are shown in Table 2.

The particularity of OTA is due to its high stability. It has been shown that it possesses a resistance to acidity and high temperatures. Thus, once foodstuffs are contaminated, it is very difficult to totally remove this molecule.

In 1982, Müller [17] showed that the OTA is only partially degraded at a normal conditions of cooking. Moreover, this molecule can resist three hours of high pressure steam sterilization of $121{ }^{\circ} \mathrm{C}$ [18], and even at $250{ }^{\circ} \mathrm{C}$ its destruction is not complete [19]. 
Gamma irradiation (up to 7,5 Mrad) of OTA in ethanol does not cause any degradation. However, degradation is observed at low moisture level when OTA has been treated with an excess of sodium hypochlorite $(\mathrm{NaOCl})[20]$. Moreover, exposure to fluorescent light is a factor of degradation.

Table 2. Spectral characteristics of ochratoxin A.

\begin{tabular}{|c|c|c|c|}
\hline Spectral & Solvents & Characteristics & References \\
\hline UV-VIS & ETOH & $\begin{aligned} \lambda \max & =213 \mathrm{~nm}(\varepsilon 36.800) \\
\lambda \max & =332 \mathrm{~nm}(\varepsilon 6.400)\end{aligned}$ & [9] \\
\hline Fluorescence & $\begin{array}{l}\text { ETOH 96\% } \\
\text { ETOH /ABS. }\end{array}$ & $\begin{aligned} \lambda \max & =467 \mathrm{~nm} \\
\lambda \max & =428 \mathrm{~nm}\end{aligned}$ & [9] \\
\hline IR & $\mathrm{CHCl}_{3}$ & $\begin{array}{l}3380 ; 2988 ; 1723 ; 1674 ; 1528 \\
1425 ; 1381 ; 1304 ; 1260 ; 1170 ; \\
1140 ; 1107 ; 827 \mathrm{~cm}^{-1}\end{array}$ & {$[10]$} \\
\hline $\begin{array}{c}\text { NMR }{ }^{1} \mathrm{H} 250- \\
\mathrm{MHZ}\end{array}$ & $\mathrm{CDCl}_{3}$ & $\begin{array}{l}\delta 12,70 ; \delta 10,80 ; \delta 8,55 \\
(3 \mathrm{H}) ; \delta 7,23 ; \delta 7,15 \\
(\mathrm{H} \mathrm{Aromatic}) ; \delta 4,71 ; \delta 5,07 \\
(\mathrm{CH}) ; \delta 2,78 ; \delta 3,2\left(\mathrm{CH}_{2}\right) ; \delta \\
1,55\left(\mathrm{CH}_{3}\right)\end{array}$ & [11-14] \\
\hline MS & - & $\begin{array}{l}\mathrm{m} / \mathrm{z} 239 / 241 \\
\mathrm{~m} / \mathrm{z} 255 / 257 \\
\text { molecular ion } \mathrm{m} / \mathrm{z} 403\end{array}$ & {$[15,16]$} \\
\hline
\end{tabular}

\section{Toxicological Profile}

The toxicological status of OTA has been examined many times and was the subject of a complete monograph by the IARC (International Agency for Research on Cancer) in 1993 [21].

Following the discovery of human and animal spontaneous nephropathies, many experimental studies were carried out in order to show the implication of OTA in these diseases [22-28]. These studies showed that this molecule can have several effects such as nephrotoxic, hepatotoxic, neurotoxic, teratogenic and immunotoxic on several species of animals, and can cause kidney and liver tumors in mice and rats, however its toxicity varies depending on the sex, the species and the cellular type of the tested animals [29]. The genotoxic status of OTA is still controversial, due to contradictory results obtained in various microbial and mammalian tests. However, evidence of DNA-adducts formation was shown following chronic exposure of OTA to rat and sub-acute exposure to pig [30].

\subsection{Nephrotoxicity}

Nephropathy is the major toxic effect of OTA. This molecule shows to be potentially nephrotoxic in all non-ruminant mammals [31]. Epidemiological studies carried out in Denmark, Hungary, Scandinavia and Poland, showed that OTA plays an important role in the etiology of porcine nephropathy [32]. This mycotoxin was also associated with human nephropathy [33-35] and it is suspected to be the cause of the human fatal disease known as Balkan Endemic Nephropathy (BEN), an interstitial chronic disease affecting the south-eastern population of Europe (Croatia, Bosnia, 
Bulgaria and Romania) [26,33-36]. It is also considered to be the major cause of the Tunisian Nephropathy (TCIN) [37] affecting the population in Tunisia.

\subsection{Neurotoxicity}

It has been shown that the administration of OTA at gestation period in rats induced many malformations in the central nervous system [38]. In the same way, Soleas et al. [39] reported that OTA can be regarded as a possible cause of certain lesions as well as damage at the cerebral level. Thus, this substance seems to be highly toxic for the nervous cells and able to reach at any time the neural tissue (brain, retina) [40].

\subsection{Teratogenicity}

OTA is a potent teratogen to laboratory animals. It can cross the placenta and accumulate in fetal tissue causing various morphological anomalies. It has been reported to elicit prenatal dysmorphogenesis in rats [41-44], mice [45], hamsters [46] and chick embryos [47]. The mechanism of OTA induced teratogenesis has not been clearly defined and may involve an indirect effect through maternal action [48] and/or a direct effect on the developing conceptus [49]. Thus, the gravity of malformations depends on the route of administration and the gestative period.

\subsection{Immunotoxicity}

Under certain conditions, OTA presents a powerful immunosuppressor effect, which is observed at low or high doses [50].

Necroses of lymphoid tissues were reported indicating there high sensitivity to the OTA [50], humoral and cellular immunity affections were also described [51].

OTA seems to play a role in the inhibition of the peripherals $\mathrm{T}$ and $\mathrm{B}$ lymphocytes proliferation and stops the production of interleukin 2 (IL2) and its receptors [52]. Moreover, it blocks the activity of killer cells as well as the production of interferon [38].

The administration of OTA to many animal species causes variable effects on the osseous marrow and immunity response. Thus, this molecule is considered to be the origin of:

- Lymphopenia,

- Regression of the thymus,

- Suppression of the immunity response.

Following these results, OTA is clearly taken as an important immunosupressor agent [49].

\subsection{Carcinogenesis}

OTA is reasonably anticipated to be a human carcinogen based on sufficient evidence of carcinogenicity in experimental animals. When this molecule was administered in the diet, hepatocellular tumors (designated as well-differentiated trabecular adenomas), renal cell tumors (renal 
cystadenomas and solid renal-cell tumors), hepatomas (some exhibiting the trabecular structure), and hyperplastic hepatic nodules were observed in male mice [53].

In another study, administration of OTA in the diet induced hepatocellular carcinomas and adenomas in female mice [54]. Gavage administration of OTA to male and female rats resulted in a dose-related increase in the incidence of renal-cell adenomas and adenocarcinomas; further, metastasis of the renal-cell tumors was also observed in male and female rats. When administered by gavage, OTA increased the incidence and multiplicity of fibroadenomas of the mammary gland in female rats $[21,55]$.

However, no adequate human studies of the relationship between exposure to OTA and human cancer have been reported. Incidence of and mortality from urothelial urinary tract tumors have been correlated with the geographical distribution of Balkan endemic nephropathy in Bulgaria and Yugoslavia [56].

\section{Ochratoxin A Producing Fungi}

OTA was isolated in 1965 from a culture of Aspergillus ochraceus (section Circumdati ) [57], but subsequent studies have revealed that a variety of fungal species included in the genera Aspergillus and Penicillium are able to produce ochratoxins [57]. A. ochraceus has been shown to consist of two species $[58,59]$. The second and new species producing large amounts of OTA consistently has been described as A. westerdijkiae. In Aspergillus section Nigri Aspergillus carbonarius [60] is a major OTA producer. It occurs in grapes, producing OTA in grape products, including grape juice, wines and dried vine fruits $[61,62]$ and sometimes in coffee beans [63,64]. Aspergillus niger aggregates have been reported as OTA producers [64-67]. The reported percentage of ochratoxigenic isolates belonging to the A. niger aggregate is much lower than A. carbonarius species [68]. A. lacticoffeatus and A. sclerotioniger are reported to produce OTA [69].

Others Aspergilli can produce OTA in large amounts, but they appear to be relatively rare. In Aspergillus section Circumdati (formerly the Aspergillus ochraceus group), the following species can produce OTA: Aspergillus cretensis, A. flocculosus, A. pseudoelegans, A. roseoglobulosus, A. sclerotiorum, A. sulphureus and Neopetromyces muricatus [59]. According to Ciegler [70] and Hesseltine, et al. [71] A. melleus, A. ostianus, A. persii and A. petrakii may produce trace amounts of OTA, but this has not been confirmed since publication of those papers. Strains of these species reported to produce large amounts of OTA were re-identified by Frisvad et al. [72]. In Aspergillus section Flavi, Petromyces albertensis produces OTA.

In the genus Penicillium, $P$. verrucosum has been regarded to be the only species of the genus Penicillium to synthesize OTA [73]. However, it has been shown that two species of the genus Penicillium have this capacity, namely $P$. verrucosum and $P$. nordicum. Penicillium verrucosum is the major producer of OTA in stored cereals [73-75]. Penicillium nordicum [76] is the main OTA producer found in meat products such as salami and ham. 


\section{Contaminated Foods}

Cereals are the most important source of human food. The annual world crop of cereals exceeds 2,000 million tones, meaning over $160 \mathrm{~kg}$ per inhabitant, and the production of cereals is still growing [77-79]. However, an investigation carried out by Pittet [80] on a worldwide scale showed that $25 \%$ to $40 \%$ of cereals are contaminated by mycotoxins. This contamination can occur in several times (in the field and/or during storage).

It is especially in the countries with hot and wet climatic conditions (in particular African countries, South Asia and South America) that the growth of toxigenic filamentous fungi is most favored. Thus, rice, corn, and millet: the basic foods of the populations of these countries, are often contaminated especially by aflatoxins and ochratoxins [81]. However, countries of Northern Europe, characterized by a low temperature climate, are especially contaminated by OTA where its production is due to a different species belonging to the Penicillium genera (P.verrucosum, P.nordicum). These are species able to grow and to produce OTA at low temperatures, which can explain the fact that these countries are more contaminated with OTA producing Penicillium species than Aspergillus ones.

Thus, worldwide, cereals are considered as being the major source of OTA contamination, where $50 \%$ of human daily intake of this mycotoxin is due to the consumption of different cereals derived products [82].

Moreover, wine was recently considered as being the second source of OTA human consumption ( $10 \%$ to $15 \%$ of the total OTA daily intake) [83-86]. Many recent works [22,26,34,83,87-90] highlight the presence of considerable levels of this toxin in wines, musts and grape juices (up to $7 \mu \mathrm{g}$ per liter). This occurrence of OTA in grape derived products was explained by the fact that grapes were contaminated in the vineyard from veraison onward, and sometimes even as soon as setting, by various ochratoxigenic species especially belonging to the genus Aspergillus section Nigri (A.carbonarius and A.niger aggregates) and that OTA production increases rapidly with maturation stages $[24,34,84,89,90]$. Thus, the date of grape harvest would have an important effect on the OTA content in grape and its derived products.

Moreover, OTA contamination of many other raw agricultural products has been well documented; such contamination occurs in a variety of food and feed, such as coffee beans, pulses, spices, meat and cheese products [91]. OTA has also been detected in other beverages such as beer.

\section{Regulation and Legislation}

In recent years, the general concern about the potential effects of mycotoxins on the health of humans and animals has been increasing. Measures have been set up by authorities in many countries to monitor and control mycotoxin levels. Various factors play a role in decision-making processes focused on setting limits for mycotoxins.

These include scientific factors to assess risk (such as the availability of toxicological data), food consumption data, knowledge about the level and distribution of mycotoxins in commodities, and analytical methodology. Economic factors, such as commercial, trade interests and food security 
issues, also have an impact. Weighing the various factors that play a role in the decision making process to establish mycotoxin tolerances is therefore of crucial importance. Despite the difficulties, mycotoxin regulations have been established in many countries during the past decades [92] and newer regulations are still being issued.

Maximum tolerable levels and guideline levels have been established in different food and feed products, often down to the ppb or ppt level [93-98]. Such regulation has been fixed for a number of mycotoxins like aflatoxins; the trichothecenes deoxynivalenol, diacetoxyscirpenol, T-2 toxin and HT-2 toxin; the fumonisins B1, B2 and B3; agaric acid; the ergot alkaloids; ochratoxin A; patulin, phomopsins; sterigmatocystin and zearalenone [99]. Respective levels are under debate for other mycotoxins.

OTA was evaluated by the Joint FAO/WHO Expert Committee on Food Additives (JECFA) in 1991 [100] and a provisional tolerable weekly intake (PTWI) of $112 \mathrm{ng} / \mathrm{kg}$ body weight (b.w.) was established. This value was proposed according to the porcine nephropathies data basis.

However, this molecule was re-evaluated by the JECFA in 1995 [101] and the PTWI was reconfirmed, rounding it to $100 \mathrm{ng} / \mathrm{kg}$ b.w. per week, and the request for further studies on OTA was re-iterated.

Since its last evaluation and after the availability of several new studies on OTA effects, the JECFA recommended at its 56th meeting in February 2001 [102] that studies should be conducted to clarify the mechanism by which OTA induces nephrotoxicity and carcinogenicity and noted that studies to resolve these issues are in progress. JECFA retained the previously established PTWI of $100 \mathrm{ng} / \mathrm{kg}$ b.w. per week, pending the results of these studies.

On the other hand, the Scientific Committee on Food (SCF) expressed its opinion on OTA on 17 September 1998 that in [103]. It stated that in the light of more recent toxicological studies and exposure data, specific attention has also been given to vulnerable groups such as infants and children and groups of consumers who are exposed to higher levels of OTA than the average consumer due to their dietary habits.

This committee proposed to reduce the OTA intake as much as possible to levels between $1.2-14 \mathrm{ng} / \mathrm{kg}$ b.w. per day.

The European Commission Regulation (EC) No. 472/2002 of 12 March 2002 [104] amended the Regulation (EC) No. 466/2001 [105] setting maximum levels for certain contaminants in foodstuffs. This regulation limits OTA contamination in unprocessed cereals, including rice and buckwheat, up to $5 \mu \mathrm{g} / \mathrm{kg}$. However, concerning cereal derived products, OTA contamination was fixed to $3 \mu \mathrm{g} / \mathrm{kg}$. This regulation fixes also the contamination of dry grapes to a limit of $10 \mu \mathrm{g} / \mathrm{kg}$.

Moreover, the regulation (EC) No. 683/2004 of April 132004 [97] amended the regulation (EC) No. 466/2001 [105] including a directive limiting the OTA contamination to $0.5 \mu \mathrm{g} / \mathrm{kg}$ in all food preparations for babies and in diet foods for special medical purposes intended specifically for infants.

Added to that, the regulation (EC) No. 123/2005 [106] highlights the contribution of many food products such as wine, grape juices and coffee in human OTA exposure. This regulation did not modify the maximum contents established previously on cereals or grapes. However, it includes a new 
directive limiting OTA contamination in grape juices, wines (red, white and rosé), and must to $2 \mu \mathrm{g} / \mathrm{L}$. Another new directive aiming to set limits for OTA contamination in coffee was taken; this one fixed a maximum level for OTA of up to $5 \mu \mathrm{g} / \mathrm{kg}$ in torrefied coffee beans and to $10 \mu \mathrm{g} / \mathrm{kg}$ in instant coffee.

According to the regulation (EC) No. 466/2001 [105], it is totally prohibited to mix non-conform products with conform ones in order to reduce OTA contamination levels. There was also an interdiction to use chemical treatments for OTA decontamination in products for human consumption.

In all cases, the aim of these directives is to estimate and to minimize the presence of OTA in various foods by implementating many plans having the objective to reduce the contamination of food products by this mycotoxin. Various strategies can be adopted in order to obtain products in agreement with the international regulations. It will be a question of observing good agricultural practices, or decontaminating the end product.

\section{Analytical Analysis of OTA}

\subsection{Chromatographical methods}

The analysis of OTA in most foodstuffs is relatively straightforward and generally reliable results are obtained, as evidenced by the results from proficiency testing. Samples need to be acid- or alkaliextracted from the foodstuffs, with alkaline extraction from most matrices showing generally better recoveries [107].

\subsubsection{Thin layer chromatography (TLC)}

TLC is featured in earlier AOAC methods [108,109], which use a silica gel adsorbent and an acidic solvent system. Since then, this method has been very commonly used in many laboratories around the world for identifying and quantifying the OTA in foodstuffs. The TLC consists of an OTA visual detection by its greenish fluorescence under long wave ultraviolet light, which changes to blue fluorescence after spraying the chromatographical plate with methanolic sodium bicarbonate solution or exposing it to ammonia fumes; scanning densitometric analysis may also be carried out. However, the detection limit makes this method inadequate for present day monitoring and compliance purposes.

\subsubsection{Liquid chromatography (LC)}

Conventionally liquid/liquid extraction and solid phase clean-up have been used prior to HPLC determination with fluorescence detection [110]. However, over the past 10 years, most laboratories have tended to move towards using immuno-affinity column clean-up because they considered it is relatively simple to carry-out and provides sample extracts generally free of interferences.

Good methods are available for dried fruit [111], beer [112,113], coffee [114,115], dried figs [107], milk [116] and wine [22,113]. Roasted coffee tends to be the most problematic of foodstuffs to analyze for OTA and in some methods an additional clean-up step is advocated prior to the affinity column stage [117]. 
Similar methodology has been used successfully to analyze blood and urine for OTA, when this biomarker approach has been employed for exposure assessment [118]. There are CEN standards for determining OTA in cereals, roasted coffee, wine and beer with limits of quantification (LOQ) ranging from $1.3 \mathrm{ng} / \mathrm{g}$ for barley [119] and coffee [120] to $5 \mathrm{pg} / \mathrm{mL}$ for wine [22].

Particular attention was paid to validating a method for OTA in baby food at an LOD and LOQ of $0.05 \mathrm{ng} / \mathrm{g}$ and $0.22 \mathrm{ng} / \mathrm{g}$ respectively, the additional sensitivity being obtained by extracting larger sample sizes and enhancing fluorescence detection by using post-column ammoniation [121]. Whereas affinity column clean-up for confirmation of results is not essential, verification of results can be undertaken by methylation of OTA followed by the observation of the shift in retention time, or by LC/MS [107].

\subsection{Immunological methods}

The use of ELISA (Enzyme linked immuno sorbent assay) for OTA analysis is considered as an important and very rapid method, because it is easy to use and due to the large number of samples that can be processed at the same time (up to 90 samples for each ELISA kit in 45 minutes), and because this method do not require any clean-up procedure. ELISA methods have been applied to quantify OTA in cereals, food, feed, animals tissues and serum [122,123]. However, an important consideration with ELISA should be taken: the specificity of the antibody. Cross reactivity with related molecules can vary widely given over-estimated values.

Radio-immunoassay (RIA) for OTA has been applied to surveys of cereals, cereal products, feedstuffs, pig serum and tissues [124-126]. OTA has been also determined by an enzyme immunosensor with an oxygen electrode [127]. However, these methods do not appear to have been used recently.

\section{Current Status on the Biosynthesis of Ochratoxin A}

Although much information exists concerning the various toxigenic properties of OTA, unlike other important mycotoxins, not very much is known about the OTA biosynthetic pathway in any fungal species. It is widely believed that the isocoumarin group is a pentaketide formed from acetate and malonate via a polyketide synthesis pathway [128-130]. Thus, a polyketide synthase (PKS), which is considered as key enzyme, is involved in the OTA biosynthesis in a similar way of other polyketide mycotoxins such as fumonisins [131] and aflatoxins [132,133].

Huff and Hamilton, [134] proposed a biosynthetic pathway based on a mechanistical model according to the structure of OTA (Figure 3). The heterocyclic portion of OTA is structurally similar to mellein, a secondary metabolite produced by many OTA producing species such as A. ochraceus, A. westerdijkiae and A. melleus. Mellein is also produced by non ochratoxigenic species such as Pezicula spp. [135], Botryosphaeria obtusa [136], Septoria nodorum [137], Phoma tracheiphila [138], Apiospora camptospora [139], Cercospora taiwanensis [140], C. scirpicola [141], Fusarium larvarum [142], Gyrostroma missouriense [139], Pezicula livida, Cryptosporiopsis malicorticis, Cryptosporiopsis sp. and Plectophomella sp. [143]. 
Figure 3. Schematic representation of the hypothetical OTA biosynthetic pathway as proposed by Huff and Hamilton, [134].

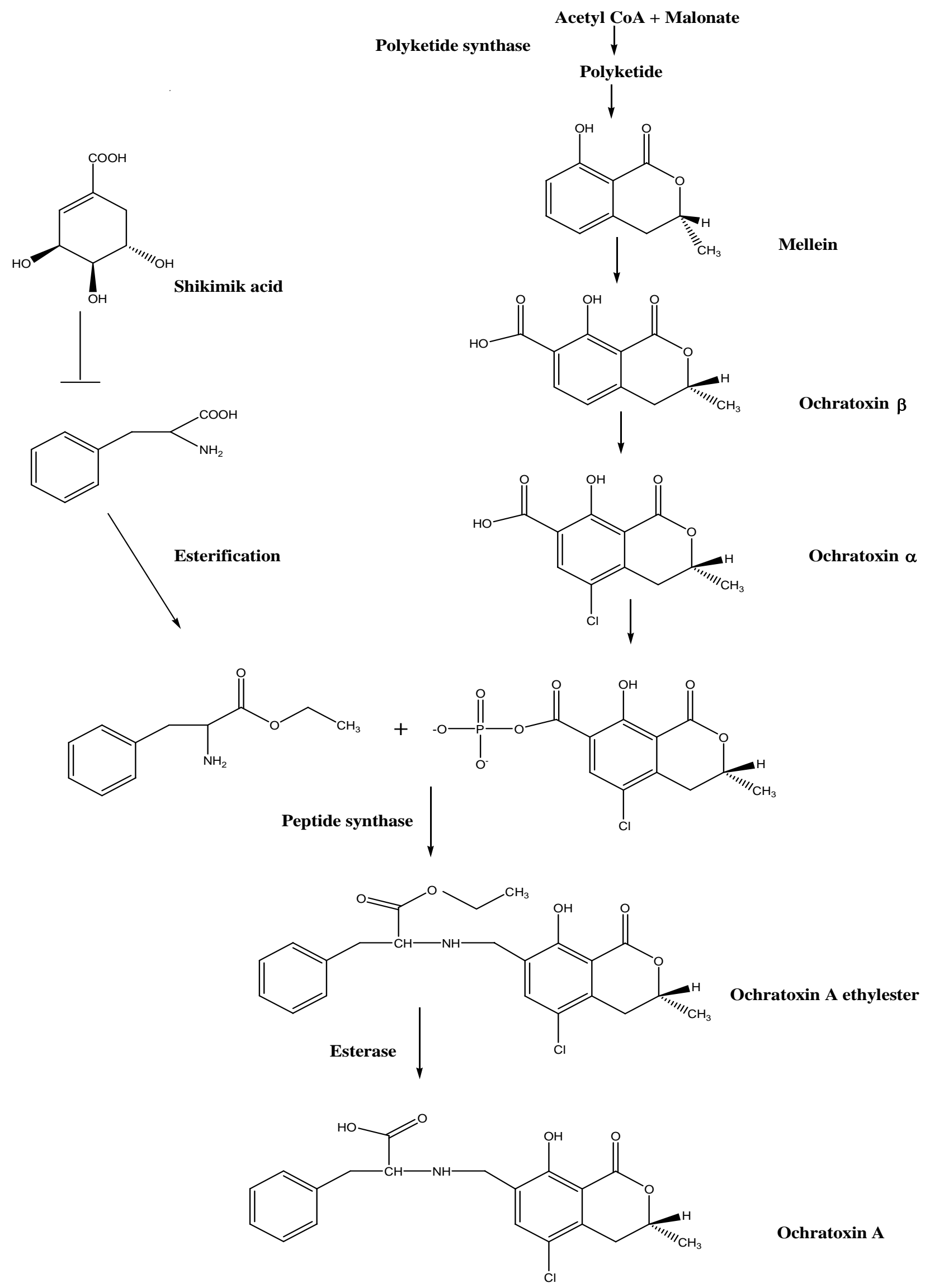


According to Huff and Hamilton, [134], three distinct steps occur in OTA biosynthesis (Figure 3): The first part is polyketide synthesis of ochratoxin $\alpha$ via mellein involving a polyketide synthase. The second step includes acyl activation: mellein is methylated and oxidized to 7-Carboxy-Mellein (=OT $\beta$ ). Chlorination by a chloroperoxidase leads to OT $\alpha$. This component is then transformed to a mixed anhydride, an activation reaction using ATP. The second precursor phenylalanine is synthesized via the shikimic acid pathway, followed by ethyl ester activation so that it can participate in the subsequent acyl displacement reaction. In the third step, linkage of those activated precursors via a synthetase takes place, generating OTC, an ethyl ester of OTA: de-esterification by an esterase or transesterification is the last step in this postulated biosynthetic pathway (Figure 3).

This schematic pathway has been dissented by Harris and Mantle [144] using labeled precursors to the growing cultures of OTA producing fungi A. ochraceus. Relative incorporation of labeled putative intermediates ochtatoxin $\alpha$ and $\beta$ and mellein indicated a strong preferential role of $\alpha$, moderate role of $\beta$, but found no role of mellein into OTA production.

At the molecular level, the study of genetic nature of polyketide has been facilitated by the introduction of molecular techniques such as Genomic DNA bank and cDNA bank construction; polymerase chain reaction (PCR); gene inactivation; differential display reverse transcriptase-PCR (DDRT-PCR); microarrays etc. PCR and subtractive PCR have been utilized to identify various PKS genes responsible for the biosynthesis of various polyketides [145-148]. Pairs of degenerated primers targeting KS domain; which is the most conserved domain among different PKSs, have been previously designed to amplify KS domain fragment from different types of PKS genes [145-147]. These degenerated primers were successfully used in OTA producing fungi. Five different PKS genes have been identified in A. ochraceus by Varga et al. [149] and Edwards et al. [129]. In addition nine different KS domains in A. westerdijkiae NRRL 3174 (=A. ochraceus) as well as five different KS domain sequences in A. carbonarius (2Mu134 = CBS 120167) [150] have been isolated.

In an attempt to elucidate the molecular biosynthetic pathway of OTA, O'Callaghan et al. [148] have previously cloned part of the polyketide synthase ( $p k s)$ gene (GeneBank accession number: AY272043) required for OTA biosynthesis in A. ochraceus, but no information was obtained concerning the presence or absence of some metabolite like the mellein. Later on, a polyketide synthase gene otapksPN (GeneBank accession number: AY196315), from P. nordicum that is essential for OTA biosynthesis was reported by Karolewiez and Geisen, [151]. Recently, Bacha et al. [152] reported the characterization of a PKS gene, awks1(or aoks1 as named by the authors), (GeneBank Accession Number: AY583209) required for the OTA biosynthesis in A. westerdijkiae. Disruption of awks1 stopped the biosynthesis of OTA, but did not affect the biosynthesis of others metabolites specially the mellein. This finding supports the results of Harris and Mantle, [144] where a mutant in which the PKS gene has been interrupted cannot synthesize OTA but still produce the mellein.

\section{Identification of Ochratoxin A Gene Cluster}

The adaptation of an organism to environmental conditions requires the cooperation of several genes that contribute to its survival. In a metabolic chain, the product of an enzymatic reaction must be 
taken very quickly by the following enzyme to ensure a correct speed of formation of the final product and avoid being destroyed by the possible reactions. So an enzymatic assembly in the form of complex or enzymatic cluster $[153,154]$ is therefore a necessity. In fungi, several clusters coding for polyketides have been studied. These clusters include clusters for the biosynthesis of mycotoxins (aflatoxins, fumonisins, ergot alkaloid, paxillin), antibiotics (cephalosporin and penicillin), melanins and some pharmaceutical products (lovastatin and compactin).

In the following paragraphs we will discuss the achievement made for the identification of OTA gene cluster in Aspergillus and Penicillium species.

\subsection{Aspergillus species}

Given that mycotoxin biosynthetic genes are often coordinately regulated $[153,154]$ and arranged in clusters [155,157], and having established that OTA production in permissive and restrictive medium appears to be dependent on pks gene transcript levels expression, O'Callaghan et al. [158] attempted to identify other putative OTA biosynthetic genes in A. ochraceus by comparing their expression profiles with that of the OTA pks gene in permissive and restrictive medium. In their study, they focused on two putative cytochrome P450 monooxygenase genes. Both genes displayed a high degree of similarity to other monooxygenase genes encoding enzymes involved in the biosynthesis of polyketide secondary metabolites. Specifically, the p450-H11 gene is very similar to the averantin oxidoreductase gene involved in aflatoxin biosynthesis [159], while the p450-B03 gene is not only similar to the trichodiene oxygenase gene from the trichothecene biosynthetic pathway in Gibberella zeae [160] but also displays significant similarity to the cypA gene in the aflatoxin biosynthetic pathway from A. flavus [161]. A strong correlation between the amount of pks and cytochrome P450 transcripts present and the amount of OTA accumulation was observed by the authors indicating a possible role for these genes in OTA biosynthesis. Additionally, O'Callaghan et al. [158] reported on the cloning of the full length pks gene and on the cloning part of a novel nonribosomal peptide synthetase (nrps) gene 900 bp upstream of the pks gene. Both the pks and nrps genes appear to be transcribed in the same direction but they are not in the same reading frame. Thus they appear to encode two separate proteins rather than a single hybrid type PKS-NRPS.

Alignment study (Figure 4) revealed that the pks gene characterized by O'Callaghan et al. [148] shares more than 98\% identity with a PKS gene awlc35-12 (or aolc35-12), identified in A. westerdijkiae $[150,162]$. This finding shows that $A$. ochraceus and $A$. westerdijkiae contain a similar gene. The pks gene also displayed similarities of $60 \%$ to a hypothetical PKS gene corresponding to the OTA cluster in A. niger [163] and only 38\% to a awks1 gene required for the biosynthesis OTA in A. westerdijkiae [152] (Figure 4). Based on the high degree of similarities between the awlc35-12 and pks genes, Bacha et al. [152] assumed that awlc35-12 could be involved in OTA biosynthesis in A. westerdijkiae. Given that awks1 is different from pks, they concluded that two PKS may be involved in the biosynthesis of OTA in A. westerdijkiae. To date, only four cases have been reported that involve two different fungal PKSs essential for a single polyketide: a set of two unusual type I multifunctional PKSs for the biosyntheses of lovastatin and compactin in A. terreus and P. citrinum, 
respectively, [164-166] and two PKS have been reported to be involved in the biosynthesis of zearaleone in G. zea [167] and T toxin in C. heterosphorus [168].

Figure 4. Alignment of the deduced amino acid sequence of ochratoxin A polyketide synthase gene: awks1 (A. westerdijkiae, Accession Number: AY583209), otapksPN (P. nordicum, Accession No.: AY557343), awlc35-12 (A. westerdijkiae, Accession No.: AY583208), pks (A. ochraceus, Accession No.: AY272043) and PKS- A. niger (hypothetical PKS gene corresponding to OTA cluster in A. niger, Accession No.: An15g07920).

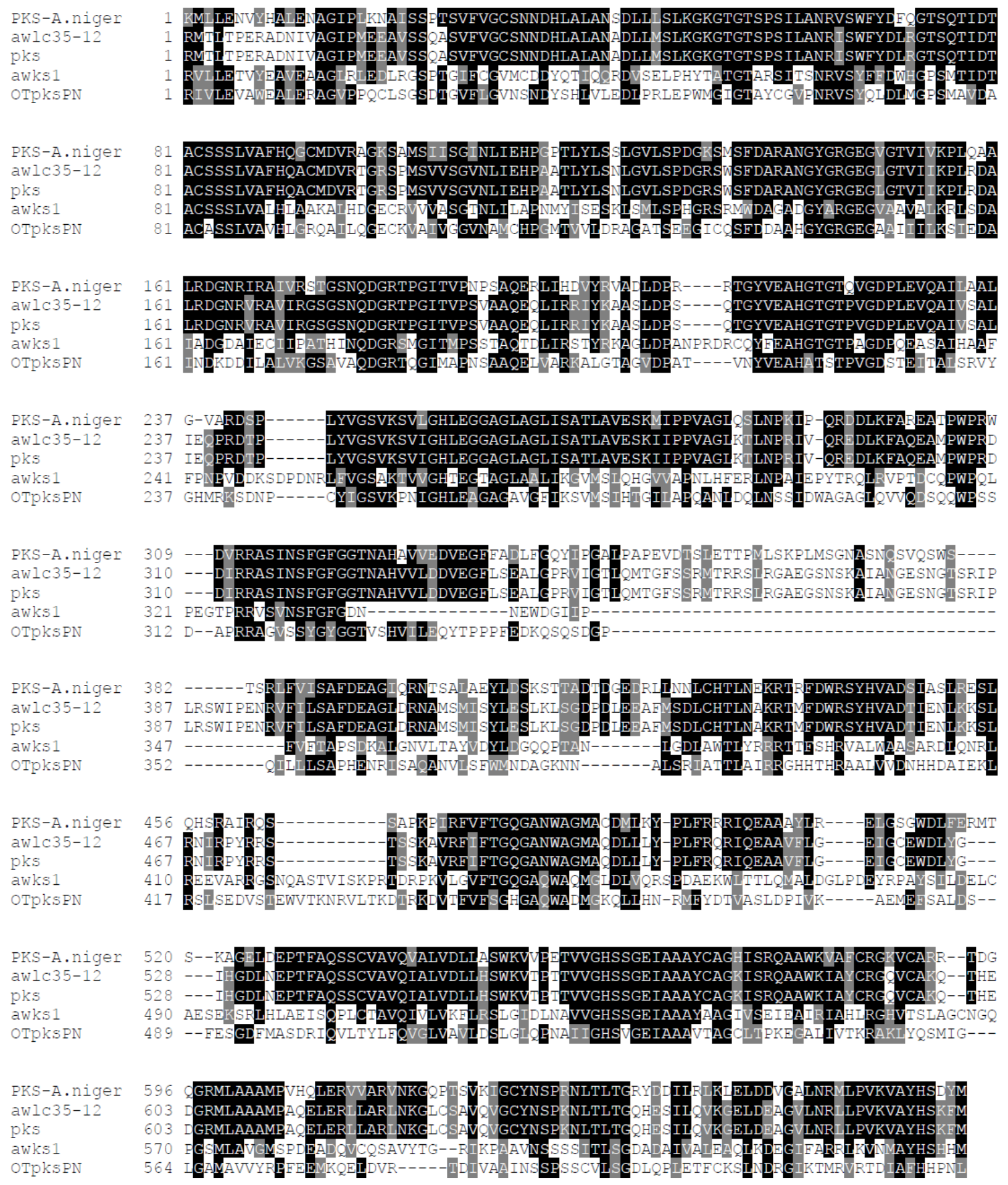


In A. carbonarius, a cDNA-AFLP differential technique was performed by Botton et al. [169] in two strains of $A$. carbonarius, antagonists to the ability of producing OTA, allowing the identification of 119 differentially expressed sequences putatively involved in the regulation of OTA biosynthesis. The differential conditions were achieved by growth on different minimal media, either supporting or inhibiting OTA production. A connection was pointed out between the biosynthesis of the toxin, vegetative growth and sexual/asexual developmental progression. A putative model for OTA biosynthesis regulation has been elaborated by the authors [169].

\subsection{Penicillium species}

Recently, most of the gene cluster responsible for the biosynthesis of OTA in Penicillium has been characterized. A $10 \mathrm{~kb}$ genomic DNA fragment of $P$. nordicum has been cloned [73,151,170,171], which carries three long open reading frames. One open reading frame (otapksPN) is a polyketide synthase, which is different from PKS genes found in Aspergillus species (Figure 4). The second open reading frame (npsPN, GeneBank accession number AY534879) has homology to non-ribosomal peptide synthetases, and the third open reading frame $(\operatorname{asp} P N)$ has homology to fungal alkaline serine proteinases. In a systematic analysis, the influence of the most important growth parameters including temperature, water activity and $\mathrm{pH}$ were analyzed by Real Time PCR and microarrays. Interestingly ,all analyzed external parameters resulted in a similar expression profile of the OTA biosynthesis genes. Interestingly the otapksPN gene is present only in $P$. nordicum but not in P. verrucosum, indicating genetic differences exist also between both OTA producing Penicillium species $[73,170,171]$.

\section{Detection of Ochratoxigenic Species by PCR}

Early and rapid detection of potential OTA producing fungi is important to reduce the negative impacts of OTA. Usual identification and quantification methods of food-borne fungi require multiple steps. Morphological and physiological tests were time-consuming and often, mycological expertise was necessary [170,172]. The PCR [173] has replaced laborious and time consuming microbiological analysis by amplification of specific genomic markers rather than growing the living organism under study. Within the last 10 years PCR systems have been developed for the detection and differentiation of major species and groups of mycotoxigenic fungi. One of the most important factors in the set up of such method is the reliability of the primer set designed and the targeted DNA sequence of interest organism [173]. Recently, various pairs of PCR primers were developed to set up novel diagnostic approaches for OTA producers in the Aspergillus and Penicillium genera.

\subsection{AFLP, RFLP, RAPD markers primers based}

Pelegrinelli-Fungaro et al. [174] described the development of a primer pair with high specificity to A. carbonarius, the main OTA producer in grapes. In their study, 29 strains of A. carbonarius, 16 A. tubingensis strains and 29 strains of $A$. niger were subjected to random-amplified-polymorphic DNA 
(or RAPD) analysis using 471 random oligonucleotides. One particular fragment of $809 \mathrm{bp}$ differentiated $A$. carbonarius from the other species. SCAR primers designed from this fragment sequence enabling differentiation of $A$. carbonarius strains from other Aspergillus spp by PCR. However, primers could not distinguish between toxigenic and non-toxigenic isolates of A. carbonarius.

Amplified fragment length polymorphism (or AFLP) marker-based primers for A. ochraceus and A. carbonarius have also been applied [175-178]. AFLP revealed high similarity of banding patterns between the A. ochraceus strains [175] and also between strains of A. carbonarius [177]. However, both OTA producers and non-producers were scattered randomly in both species analysed. These findings were in strict contrast with results obtained by Castella et al. [179]. In their study, Castella et al. [179] classified 66 strains of P. verrucosum in two distinct genotypes based on AFLP and RFLP analysis. The two RAPD as well as the two AFLP groups were completely coincidental. Strains in the two groups differed in their ability to produce OTA, with group I containing mainly high producing strains, and group II containing moderate to non-producing strains.

\subsection{Gene-based approaches for the diagnosis of ochratoxigenic fungi}

Several genes such as rRNA, $\beta$-tubulin, elongation factor $1 \alpha$ and the calmodulin genes provide highly conserved as well as variable sequence regions. Based on the alignment of a partial sequence of calmodulin genes from representative strains of A. niger group, A. carbonarius, A. japonicus and A. aculeatus, Perrone et al. [180] detected a high degree of homology between strains assigned to A. carbonarius (99.98\%) and also between strains of A. japonicus and A. aculeatus (99.40\%). Based on variable regions, the authors found three different regions suitable for designing species-specific PCR primers. The assay was useful in screening vast numbers of isolates of black aspergilli from grapes in order to evaluate the toxigenic potential connected with this commodity. Recently, Susca et al. [181] developed species-specific primers based on partial calmodulin gene sequences to identify A. carbonarius and A. niger by PCR. Moreover, a primer pair targeting the conserved regions of the A. carbonarius calmodulin gene has also been developed by Mulè et al. [182], allowing only the amplification of $A$. carbonarius strains.

Morello et al. [183] found genetic variation between the $\beta$-tubulin gene sequences from A. ochraceus and $A$. westerdijkiae allowed to design a primer-pair specific to $A$. westerdijkiae. Using these primers, no PCR product from DNA of A. ochraceus was obtained while all isolates of A. westerdijkiae gave positive results.

The coding portions of many fungal $18 \mathrm{~S}, 5.8 \mathrm{~S}$ and $28 \mathrm{~S}$ rDNA genes are highly conserved and primers to these regions have been generated [184]. The internal transcribed spacer sequences (ITS-1 and ITS-2) and IGS [185] contains hypervariable regions leading to most of the intraspecies sequence diversity [186-189]. The ITS region is amplified from the target fungus and sequenced to identify regions of DNA unique to the fungus of interest. Polymorphism within the ITS region is generally (but not always) at the level of species, rather than between isolates of the same species, making it an ideal target for the development of species-specific PCR assays. For example the species-specific primers 
have been designed on the basis of ITS sequence to discriminate the main species included in section Nigri: A. japonicus, A. heteromorphus, A. ellipticus and the two morphologically indistinguishable species of the A. niger aggregate: A. niger and A. tubingensis [190]. Other species-specific PCR-based assays to ochratoxigenic species were developed for A. carbonarius and A. ochraceus based on ITS [191].

Restriction digestion analysis of the ITS products was tested to assess its effectiveness as a rapid method to identify different isolates of black Aspergillus species from grapes [185].

Among the PCR based approaches, Accensi et al. [192] used a PCR-RFLP technique to distinguish A. niger and $A$. tubingensis isolates. The authors used the restriction enzyme RsaI to digest the amplified ITS region of the isolates, and observed that isolates of the $A$. niger species complex exhibit two different RFLP patterns, $\mathrm{N}$ and $\mathrm{T}$ corresponding to A. niger and A. tubingensis isolates, respectively. Other restriction enzymes has also been used for species identification recently using PCR-RFLP analysis of the ITS region [185]. The authors used HhaI, NlaIII and RsaI to distinguish between A. niger, A. tubingensis, A. carbonarius and A. aculeatus isolates came from grapes. Zanzotto et al. [193] used PCR-RFLP analysis of the ITS, IGS and $\beta$-tubulin genes to distinguish between OTA-producing and non-producing isolates of the A. niger aggregate.

\subsection{Using mycotoxin biosynthetic gene for identifying of ochratoxigenic fungi}

In some instances, species specific detection is not always of primary objective. It may be more relevant to determine whether the producers of particular mycotoxins are present rather than to identify exactly what the species are. This is particularly important where a mycotoxin can be produced by a number of species. Many mycotoxin biosynthetic genes are present within gene clusters, and some of these appear to have undergone horizontal transfer from one species to another and are now present in several species $[153,194]$. Regions of homology within mycotoxin biosynthetic gene from the different species can be used to develop primers to detect the presence of the relevant mycotoxigenic species. This strategy was successfully applied for aflatoxin producers [195,196], trichothecene-producing fungi [197-199], fumonisin-producing Fusarium species [198-200] and also for producers of patulin [198,201].

In A. ochraceus, the sequence of AoLC35-12 (accession nb:AY583208) was found to join a sequence encoding for acyl transferase domain of a polyketide synthase [150,162], which is involved in the OTA biosynthesis pathway [142]. Dao et al. [162] designed two sets of specific primers, AoLC35-12L/AoLC35-12R and AoOTAL/AoOTAR, from AoLC35-12. The set primers AoOTAL/AoOTAR specifically detected A. ochraceus by PCR method. Because A. ochraceus and A. westerdijkiae were only recently dismembered into two species, the primer-pairs designed until now are not specific either to A. ochraceus or to A. westerdijkiae, i.e., they recognize both species. The second primer pair AoLC35-12L/AoLC35-12R was found to detect OTA producing fungi A. carbonarius, A. melleus, A. ochraceus, A. sulfureus, P. verrucosum and citrinin producing $P$. citrinum and Monascus ruber. 
In A. carbonarius, five different KS domain sequences (AcKS9, AcKS10, Ac12RL3, AcLC35-4 and AcLC35-6) were identified by Atoui et al. [150]. Two different PCR species specific detection systems were developed based on primers designed from AcKS10 [202] and Ac12RL3 [203] proved to be highly specific, yielding amplification only in A. carbonarius strains, the main OTA producer in grapes.

In the genus Penicillium, a PCR method for differentiation and detection of two ochratoxingenic Penicillium species, $P$. nordicum and $P$. verrucosum, has been developed. It is based upon two genes of the OTA biosynthetic pathway, namely the OTA polyketide synthase gene (otapks $P N$ ) and a nonribosomal peptide syntethase gene (otanps $P N$ ) from $P$. nordicum $[73,170]$. $P$. verrucosum gives consistently only a positive reaction with the primers for the otanpsPN gene, whereas $P$. nordicum is positive for both genes. The PCR reaction is negative with all of other food related fungal species tested. This system has been used to analyze 62 Penicillium strains isolated from cured meat products or ripening rooms.

\section{Application of PCR for the Detection and Quantification of OTA Producers in Contaminated Commodities}

Recent advances in DNA-based techniques such as real-time PCR (RT-PCR) are providing new tools for fungal detection and quantification by detecting and quantifying their DNA. RT-PCR can be performed using different chemistries, such as SYBR ${ }^{\circledR}$ Green I dye [204,205] and TaqMan ${ }^{\circledR}$ [206]. Both systems have proven useful in monitoring and quantification of OTA fungal producer in many food commodities [73,170,176,182,202,203].

One of the major motivations for the development of PCR based detection systems in many publications is the prospect of using this kind of analysis to estimate OTA concentrations in sample material. One might therefore anticipate that assays based on OTA biosynthetic genes might better fit that purpose as compared to systems based on genes unrelated to their biosynthesis. By using real-time PCR, a positive correlation between OTA content and DNA quantity has been indicated for $P$. nordicum and A. ochraceus [164,170] and more recently, in A. carbonarius [182,202,203]. Such a correlation has been established with quantitative real-time PCR on mycotoxin biosynthesis genes [73] or when using primers targeted sequences of housekeeping genes [182].

Currently, RT- PCR quantification of A. carbonarius in grapes is clearly the best alternative to conventional methods in order to investigate the relation between OTA producers and OTA content. With regards to food safety, Atoui et al. [203] established, according to their correlation, that $A$. carbonarius DNA content has to be lower than 10 ng DNA g-1 grape berry to fulfill the maximum OTA permitted levels in the European Union (Commission regulation No. 123/2005 amending Regulation No. 67 446/2001 as regards to ochratoxin A).

All the systems described above are based on PCR with genomic target DNA as template to estimate OTA concentrations in sample materials. Given the fact that biosynthesis of most mycotoxins is a highly complex process with poorly understood regulation at the transcriptional level as well as 
being highly influenced by environmental factors; it is important to find correlation between gene expression and concentrations of compounds.

A RT-PCR system based on the otapksPN sequence has been used to monitor growth and OTA production of $P$. nordicum in wheat $[73,170]$. A strong correlation between the copy numbers of the otapksPN gene and the colony forming units (cfu) was observed. In addition, there was a strong congruence between otapksPN gene expression and OTA production in wheat. It can be used for the rapid quality assessment of food products by quantitative determination of the fungal biomass. It can further be used for HACCP (hazard analysis critical control point) purposes to determine the critical control points $\left(\mathrm{CCP}^{\prime} \mathrm{s}\right)$ during the production chain under which otapksPN gene expression and thereby OTA production is possible.

With the available systems of PCR-based detection and quantification of ochratoxin A described in this review, the choice of the best method depends on the goal of the study to be conducted. For example, AFLP and RAPD could be the best choice when the purpose of the study is (1) to show the polymorphism of some isolated strains belonging to the same species or (2) to discriminate between relevant OTA producer species. On the other hand, when dealing with the detection of the fungus, the best way is to conduct conventional PCR using primers designed from housekeeping genes or mycotoxin biosynthetic genes as described in sections 11.2 and 11.3. Concerning the application of the described molecular techniques in food, AFLP and RAPD show limitations such as fungal isolation and preparation of DNA of very high quality. For this reason Real time PCR technology provides an insight into the mycotoxigenic status of food sample as well as it has the power to estimate its mycotoxin content.

\section{References}

1. Keeper-Goodman, T.; Scott, P.M. Risk assessment of the mycotoxin ochratoxin. Biomed. Environ. Sci. 1989, 2, 179-248.

2. Miller, J.D.; Trenholm, H.L. Mycotoxins in Grain: Compounds Other than Aflatoxin; Eagan Press: St. Paul, MN, USA, 1994.

3. Bredenkamp, M.W.; Dillen, J.L.M.; Van Rooyen, P.H.; Steyn, P.S. Crystal structures and conformational analysis of ochratoxin A and B: Probing the chemical structure causing toxicity. J. Chem. Soc. 1989, 2, 1835-1839.

4. Budavari, S. The Merck Index, 11th ed.; Rahway, N.J., Ed.; Merck \& Co.: Rahway, NJ, USA, 1989; pp. 30-31.

5. Faucet-Marquis, V.; Pont, F.; Størmer, F.C.; Rizk, T.; Castegnaro, M.; Pfohl Leszkowicz, A. Evidence of a new dechlorinated ochratoxin A derivative formed in opossum kidney cell cultures after pretreatment by modulators of glutathione pathways: Correlation with DNA-adduct formation. Mol. Nurt. Food Res. 2006, 50, 530-542.

6. Tozlovanu, M.; Faucet-Marquis, V.; Pfohl-Leszkowicz, A.; Manderville, R. Genotoxicity of the hydroquinone metabolite of ochratoxin A: Structure-activity relationships for covalent DNA adduction. Chem. Res. Toxicol. 2006, 19, 1241-1247 
7. Pfohl-Leszkowicz, A.; Manderville, R.A. Ochratoxin A: An overview on toxicity and carcinogenicity in animals and humans. Mol. Nutr. Food Res. 2007, 51, 61-99.

8. Manderville, R.A.; Pfohl-Leszkowicz, A. Bioactivation and DNA adduction as a rationale for ochratoxin A carcinogenesis. World Mycotoxin J. 2008, 1, 357-367

9. Miller, J.D. Fungi as contaminants in indoor air. Atmos. Environ. 1992, 26, 2163-2172.

10. Steyn, P.S. Ochratoxin and related dihydroisocoumarins. In Mycotoxin-Production, Isolation, Separation and Purification; Betina, V., Ed.; Elseiver: Amsterdam, The Netherlands, 1984; pp. 183-216

11. de Jesus, A.E.; Steyn, P.S.; Vleggaar, R.; Wessels, P.A. Carbon-13 nuclear magnetic resonance assignments and biosynthesis of the mycotoxin ochratoxin A. J. Chem. Soc. 1980, 1, 52-54.

12. Pohland, A.E.; Schüller, P.L.; Steyn, P.S.; van Egmond, H. Physico-chemical data for selected mycotoxins. Pure Appl. Chem. 1982, 54, 2219-2284.

13. EL Khoury, A. Champignons Mycotoxinogènes et Ochratoxine A (OTA) et Aflatoxine B1 (AFB1) dans les Vignobles Libanais: Occurrence et Origine; Ph.D. Thesis, INP: Toulouse, France, 2007.

14. Lillehoj, E.B.; Goransson, B. Occurrence of ochratoxin and citrinin producing fungi on developing Danish barley grain. Acta Pathol. Microbiol. Scand. B 1980, 88, 133-137

15. Abramson, D. Measurement of ochratoxin A in barely extracts by liquid chromatography mass spectrometry. J. Chromatogr. 1987, 391, 315-320.

16. Bauer, J.; Gareis, M. Ochratoxin A im der Nahrungsmittelkette. J. Vet. Med. Ser. B. 1987, 34, 613.

17. Müller, H.M. Decontamination of mycotoxins. I. Physical process. Ubersicht. Tierernähr. 1982, 10, 95-122.

18. Trivedi, A.B.; Doi, E.; Kitabatake, N. Detoxification of ochratoxin A on heating under acidic and alkaline conditions. Biosci. Biotech. Biochem. 1992, 56, 741-745.

19. Boudra, H.; Le Bars, P.; Le Bars, J. Thermostability of ochratoxin A in wheat under two moisture conditions. Appl. Environ. Microbiol. 1995, 61, 1156-1158.

20. Castegnaro, M.; Barek, J.; Frémy, J.M.; Lafontaine, M.; Miraglia, M.; Sansone, E.B.; Telling, G.M. Laboratory Decontamination and Destruction of Carcinogens in Laboratory Wastes: Some Mycotoxins; International Agency for Research on Cancer: Lyon, France, 1991.

21. IARC. Some naturally occurring substances, food items and constituents, heterocyclic aromatic amines and mycotoxins. In Monograph on evaluation of carcinogenic risks to humans; IARC: Lyon, France, 1993.

22. Zimmerli, B.; Dick R. Ochratoxin A in table wine and grape-juice: Occurrence and risk assessment. Food Addit. Contam. 1996, 13, 655-668.

23. Delage, N.; d'Harlingue, A.; Colonna, B.; Ceccaldi, B.C.; Bompeix, G. Occurrence of mycotoxins in fruit juices and wines. Food Control 2003, 14, 225-227.

24. Da Rocha Rosa, C.A.; Palacios, V.; Combina, M.; Fraga, M.E.; De Oliveira Rekson, A.; Magnoli, C.E.; Dalcero, A.M. Potential ochratoxin A producers from wine grapes in Argentina and Brazil. Food Addit. Contam. 2002, 19, 408-414. 
25. Shephard, G.S.; Fabiani, A.; Stockenstrom, S.; Mshicileli, N.; Sewram, V. Quantitation of ochratoxin A in South African wines. J. Agric. Food. Chem. 2003, 51, 1102-1106.

26. Visconti, A.; Pascale, M.; Centoze, G. Determination of ocratoxin A in wine by means of immunoaffinity column clean-up and high-performance liquid chromatography. J. Chromatogr. A 1999, 864, 89-101.

27. Ospital, M.; Cazabeil, J.M.; Betbede, A.M.; Tricard, C.; Creppy, E.; Medina, B. L'Ochratoxine A dans les vins. Enologie 1998, 169, 16-19.

28. Otteneder, H.; Majerus, P. Occurence of ochratoin A (OTA) in wines: Influence of the type of wine and its geographical origin. Food Addit. Contam. 2000, 17, 793-798.

29. O'Brien, E.; Heussner, A.H.; Dietrich, D.R. Species-, sex-, and cell type-specific effects of ochratoxin A and B. Toxicol Sci. 2001, 63, 256-264

30. Faucet, V.; Pfohl-Leszkowicz, A.; Dai, J.; Castegnaro, M.; Manderville, R.A. Evidence for covalent DNA adduction by Ochratoxin A following chronic exposure to rat and subacute exposure to pig. Chem. Res. Toxicol. 2004, 17, 1289-1296.

31. Ribelin, W.E.; Fukushima, K.; Still, P.E. The toxicity of ochratoxin A to ruminants. Can. J. Comp. Med. 1978, 42, 172-176.

32. Elling, F.; Nelsen, J.P.; Lillehoj, E.B.; Thomassen, M.S.; Stormer, F.C. Ochratoxin A induced porcine nephropathy: Enzyme and ultrastructural changes after short-term exposure. Toxicon 1985, 23, 247-254.

33. Lopez de Cerain, A.; Gonzalez-Penas, E.; Jimenez, A.M.; Bello, J. Contribution to the study of ochratoxin A in Spanish wines. Food Addit. Contam. 2002, 19, 1058-1064.

34. Bejaoui, H. Champignons Ochratoxinogènes et Ochratoxine A (OTA) dans des Vignobles Français et procEdés Biologiques de décontamination de l'OTA dans les moûts de raisin; Ph.D. Thesis, INP: Toulouse, France, 2005.

35. Pfohl-Leszkowicz, A. Ochratoxin A and aristolochic acid involvement in nephropathies and associated urothelial tract tumours. Arh. Hig. Rada. Toksikol. 2009, 60, 465-483.

36. Markaki, P.; Delpont, C.; Delpont-Binet, C.; Grosso, F.; Dragacci, S. Determination of ochratoxin A in red wine and vinegar bu immunoaffinity high-pressure liquid chromatography. $J$. Food Prot. 2001, 64, 533-537.

37. Hassen, W.; Abid-Essafi , S.; Achour, A.; Guezzah, N.; Zakhama, A.; Ellouz, F.; Creppy, E.E.; Bacha, H. Karyomegaly of tubular kidney cells in human chronic interstitial nephropathy in Tunisia: Respective role of Ochratoxin A and possible genetic predisposition. Hum. Exp. Toxicol. 2004, 23, 339-346

38. Pfohl-Leszkowicz, A.; et Castegnaro, M. L'Ochratoxine A dans: Mycotoxines: Evaluation et gestion du risqué, Lavoisier; Tec \& Doc: Paris, France, 1999; pp. 249-278.

39. Soleas, G.J.; Yan, J.; Goldberg, D.M. Assay of ochratoxin A in wine and beer by high-pressure liquid chromatography photodiode array and gas chromatography mass selective detection. $J$. Agric. Food Chem. 2001, 49, 2733-2740. 
40. Brown, M.H.; Szczech, G.M.; Purmalis, B.P. Teratogenic and toxic effects of ochratoxin A in rats. Toxicol. Appl. Pharmacol. 1976, 37, 331-338

41. Mayura, K.; Reddy, R.V.; Hayes, A.W.; Berndt, W.O. Embryocidal, fetotoxic and teratogenic effects of ochratoxin A in rats. Toxicology 1982, 25, 175-185

42. Mayura, K.; Parker, R.; Berndt, W.O.; Philips, T.D. Effect of simultaneous prenatal exposure to ochratoxin A and citrinin in the rat. Toxicol. Environ. Health 1984, 13, 553-561

43. Mayura, K.; Stein, A.E.; Berndt, W.O.; Philips, T.D. Teratogenic effects of ochratoxin A in rats with impaired renal function. Toxicology 1984, 32, 277-285

44. Mayura, K.; Parker, R.; Berndt, W.O.; Philips, T.D. Ochratoxin A-induced teratogenesis in rats: Partial protection by phenylalanine. Appl. Environ. Microbiol. 1984, 48, 1186-1188

45. Hayes, A.W.; Melton, R.; Smith, S.J. Effect of aflatoxin B, ochratoxin A and rubratoxin B on a protozoan, Tetrahymena pyriformis HSM. Bull. Environ. Contamin. Toxicol. 1974, 11, 321-325.

46. Hood, R.D., Naughton, M.J.; Hayes, A.W. Prenatal effects of ochratoxin A in hamsters. Teratology 1976, 13, 11-14.

47. Gilani, S.H.; Bancroft. J.; Reily. M. Teratogenicity of ochratoxin A in chick embryos. Toxicol. Appl. Pharmacol. 1978, 46, 543-546.

48. More, J.; Galtier, P.; Alvinerie, M. Toxicite de l'ochratoxine A. III. Effets pendant les stades initiaux de la gestation chez le rat. Ann. Rech. Vet. 1978, 9, 169-173.

49. Petzinger, E.; Weidenbach, A. Mycotoxins in the food chain: The role of ochratoxins. Livest.Prod. Sci. 2002, 76, 245-250.

50. Creppy, E.E.; Betbeder, A.M.; Gharbi, A.; Counord, J.; Castegnaro, M.; Bartsch, H.; Moncharmont, P.; Fouillet, B.; Chambon, P.; Dirheimer, G. Human ochratoxicosis in France. In Mycotoxins, Endemic Nephropathy and Urinary Tract Tumours; Castegnaro, M., Plestina, R., Dirheimer, G., Chernozemsky, I.N., Bartsch, H., Eds.; IARC Scientific Publ.: Lyon, France, 1991.

51. Holmberg, T.; Thuvander, A.; Hult, K. Ochratoxin A as a suppressor of mitogen-induced blastogenesis of porcine blood lymphocytes. Acta Vet. Scand. 1988, 29, 219-223.

52. Lea, T.; Steien. K.; Stormer. C. Mechanism of ochratoxin A induced immunosuppresion. Mycopathologia 1989, 107, 153-159.

53. Huff, W.E.; Kubena, L.F.; Harvey, R.B.; Phillips, T.D. Efficacy of hydrated sodium calcium aluminosilicate to reduce the individual and combined toxicity of aflatoxin and ochratoxin A. Poult Sci. 1992, 71, 64-69

54. Pfohl-Leszkowicz, A.; Pinelli, E.; Bartsch, H.; Mohr, U.; Castegnaro, M. Sex- and strain-specific expression of cytochrome P450s in ochratoxin A-induced genotoxicity and carcinogenicity in rats. Mol. Carcinog. 1998, 23, 76-85.

55. NTP. Toxicology and Carcinogenesis Studies of Ochratoxin A (CAS No. 303-47-9) in F344/N Rats (Gavage Studies). Technical Report Series No 358; NTIS Publication No. PB90219478/AS; National Toxicology Program: Research Triangle Park, NC and Bethesda, MD, USA, 1989. 
56. Feier, D.; Tofana, M. Ochratoxin A-Toxicological Aspects. Bulletin of University of Agricultural Sciences and Veterinary Medicine Cluj-Napoca. Agriculture 2009, 66, 308-312.

57. Van der Merve, K.J.; Steyn, P.S.; Fourie, L.; Scott, D.B.; Theron, J.J. Ochratoxin A, a toxic metabolite produced by Aspergillus ochraceus. Nature 1965, 205, 1112-1113.

58. Varga, J.; Rigó, K.; Téren, J.; Mesterházy, Á. Recent advances in ochratoxin research I. Production, detection and occurrence of ochratoxins. Cereal Res. Commun. 2001, 29, 85-92.

59. Frisvad, J.C.J.; Frank, M.; Houbraken, J.A.M.P.; Kuijpers, A.F.A.; Samson, R.A. New ochratoxin A producing species of Aspergillus section Circumdati. Stud. Mycol. 2004, 50, $23-43$.

60. Horie, Y. Productivity of ochratoxin A of Aspergillus carbonarius in Aspergillus section Nigri. Nippon Kingakukai Kaiho 1995, 36, 73-76.

61. IARC. IARC Handbooks of Cancer Prevention. Weight Control and Physical Activity; International Agency for Research on Cancer: Lyon, France, 2002.

62. Leong, S.; Hocking, A.D.; Pitt, J.I. Occurrence of fruit rot fungi (Aspergillus section Nigri) on some drying varieties of irrigated grapes. Aust. J. Grape Wine Res. 2004, 10, 83-88.

63. Taniwaki, M.H.; Pitt, J.I.; Teixeira, A.A.; Iamanaka, B.T. The source of ochratoxin A in Brazilian coffee and its formation in relation to processing methods. Int. J. Food Microbiol. 2003, 82, 173-179,

64. Abarca, L.M.; Accensi, F.; Cano, J.; Cabanes, J.F. Taxonomy of black aspergilli. Ant. van Leeuwen. 2004, 86, 33-49.

65. Dalcero, A.; Magnoli, C.; Hallak, C.; Chiacchiera, S.M.; Palacio, G.; Rosa, C.A. Detection of ochratoxin $\mathrm{A}$ in animal feeds and capacity to produce this mycotoxin by Aspergillus section Nigri in Argentina. Food Addit. Contam. 2002, 19, 1065-1072.

66. Magnoli, C.; Violante, M.; Combina, M.; Palacio G.; Dalcero, A. Mycoflora and ochratoxinproducing strains of Aspergillus section Nigri in wine grapes in Argentina. Lett. Appl. Microbiol. 2003, 37, 179-184.

67. Battilani, P.; Giorni, P.; Pietri, A. Epidemiology of toxin producing fungi and ochratoxin A occurrence in grape. Eur. J. Plant Pathol. 2003, 109, 715-722.

68. Samson, R.A.; Hoekstra, E.S.; Frisvad, J.C. Introduction to Food and Airborne Fungi, 7th ed.; Centraalbureau voor Schimmelcultures: Utrecht, The Netherlands, 2004.

69. Abarca, M.L.; Accensi, F.; Bragulat, M.R.; Cabanes, F.J. Current importance of ochratoxin A producing Aspergillus spp. J. Food Protec. 2001, 903-906.

70. Ciegler, A. Bioproduction of ochratoxin A and penicillc acid by members of the Aspergillus ochraceus group. Can. J. Microbiol. 1972, 18,631-636

71. Hesseltine, C.W.; Vandegraft, E.E.; Fennell, D.I.; Smith, M.L.; Shotwell, O.L. Aspergilli as ochratoxin producers. Mycologia 1972, 64, 539-550.

72. Frisvad, J.C. Creatine sucrose agar, a differential medium for mycotoxin producing terverticillate Penicillium species. Lett. Appl. Microbiol. 1985, 1, 109-113. 
73. Geisen, R.; Mayer, Z.; Karolewiez, A.; Farber, P. Development of a real time PCR system for detection of Penicillium nordicum and for monitoring ochratoxin A production in foods by targeting the ochratoxin polyketide synthase gene. Syst. Appl. Microbiol. 2004, 27, 501-504.

74. Pitt, J.I. Penicillium viridicatum, Penicillium verrucosum, and production of ochratoxin A. Appl. Environ. Microbiol. 1987, 53, 266-269.

75. Lund, F.; Frisvad, J.C. Penicillium verrucosum in cereals indicates production of ochratoxin A. J. Appl. Microbiol. 2003, 95, 1117-1123.

76. Larsen, T.O.; Svendsen, A.; Smedsgaard, J. Biochemical characterization of ochratoxin Aproducing strains of the genus Penicillium. Appl. Environ. Microbiol. 2001, 67, 3630-3635.

77. Eskola, M. Study on Trichothecenes, Zearalenone and Ochratoxin A in finnish Cereals: Occurrence and Analytical Techniques; Academic dissertation: Skillman, NJ, USA, 2002.

78. FAO. Agro-ecological assessment for national planning: The example of Kenya. FAO soils bulletin No 67. Roma, Italy, 1993.

79. FAO/WHO. Ochratoxin A. In Safety evaluation of certain mycotoxins in food, Prepared by the 56th Meeting of the Joint FAO/WHO Expert Committee on Food Additives (JECFA). WHO Food Additives Series 47; World Health Organisation: Geneva, Switzerland, 2001; pp. 281-387.

80. Pittet, A. Natural occurrence of mycotoxins in foods and feeds an updated review. Rev. Med. Vet. 1998, 149, 479-492.

81. Nguyen, M.T.; Tozlovanu, M.; Tran, T.L.; Pfohl-Leszkowicz, A. Occurrence of afl atoxin B1, citrinin and ochratoxin $\mathrm{A}$ in rice in five provinces of the central region of Vietnam. Food Chem. 2007, 105, 42-47.

82. Vega, M.; Muñoz, K.; Sepúlveda, C.; Aranda, M.; Campos, V.; Villegas, R., Villarroel, O. Solidphase extraction and HPLC determination of ochratoxin A in cereals products on Chilean market. Food Control 2009, 20, 631-634

83. Otteneder, H.; Majerus, P. Occurrence of ochratoxin A in wines: Influence of the type of wine and its geographical origin. Food Addit. Contam. 2000, 17, 793-798.

84. Cabañes, F.J.; Accensi, F.; Bragulat, M.R.; Abarca, M.L.; Castella, G.; Minguez, S.; Pons, A. What is the source of Ochratoxin A in wine? Int. J. Food Microbiol. 2002, 79, 213-215.

85. Stefanaki, I.; Foufa, E.; Tsatsou-Dritsa, A.; Dais, P. Ochratoxin A concentrations in Greek domestic wines and dried vine fruits. Food Addit. Contam. 2003, 20, 74-83.

86. Shephard, G.S.; Fabiani, A.; Stockenstrom, S.; Mshicileli, N.; Sewram, V. Quantitation of ochratoxin A in south African wines. J. Agri. Food Chem. 2003, 51, 1102-1106.

87. Castellari, M.; Fabbr, S.; Fabiani, A.; Amati, A.; Galassi, S. Comparison of different immunoaffinity clean-up procedures for high-performance liquid chromatographic analysis of ochratoxin A in wines. J. Chromatogr. A 2000, 888, 129-136.

88. Serra, R.; Abrunhosa, L.; Kozakiewicz, Z.; Venâncio, A. Black Aspergillus species as ochratoxin A producers in Portuguese wine grapes. Int. J. Food Microbiol. 2003, 88, 63-68. 
89. Bejaoui, H.; Mathieu, F.; Taillandier, P.; Lebrihi A. Biodegradation of ochratoxin A by Aspergillus section Nigri species isolated from French grapes: A potential means of ochratoxin A decontamination in grape juices and musts. FEMS Microbiol. Lett. 2006, 255,203-208.

90. EL Khoury, A.; Rizk, T.; Lteif, R.; Azouri, H.; Delia, M.L.; Lebrihi, A. Occurrence of ochratoxin A and aflatoxin B1-producing fungi in Lebanese grapes and OTA content in musts and finished wines during year 2004. J. Agri. Food Chem. 2006, 54, 8977-8982.

91. Wolff, J.; Bresch, H.; Cholmakov-Bodechtel, C.; Engel, G.; Garais, M.; Majerus, P.; Rosner, H.; Scheuer, R. Ochratoxin A: Contamination of foods and consumer exposure. Arch Lebensm hyg. 2000, 51, 181-128.

92. FAO. Aflatoxin Contamination in Foods and Feeds in the Philippines. Document 13. FAO/WHO Regional Conference on Food Safety for Asia and Pacific Seremban, Malaysia, 2004.

93. Hussein, H.S.; Brasel, J.M. Toxicity, metabolism, and impact of mycotoxins on humans and animals. Toxicology 2001, 167, 101-134.

94. Van Egmond, H.P.; Svensson, U.K.; Fremy, J.M. Mycotoxins. Int. Dairy Fed. S.I. 1997, 79-88.

95. Commission Regulation (EC) No 466/2001 of 8 March 2001 setting maximum levels for certain contaminants in foodstuffs. Off. J. Eur. Commun. 2001, L77-L113.

96. European Commission. Commission regulation (EC) No 2003/100/EC of 31 October 2003 amending Annex I to Directive 2002/32/EC of the European Parliament and of the Council on undesirable substances in animal feed. Off. J. Eur. Commun. 2003, 285, 33-37.

97. European Commission. Commission Regulation (EC) No 2004/683/EC of 13 April 2004 amending Regulation (EC) No 466/2001 as regards aflatoxins and ochratoxin A in foods for infants and young children (Text with EEA relevance). Off. J. Eur. Commun. 2004, 106, 3-5.

98. European Commission. 2003. Commission Regulation (EC) No 2003/2174/EC of 12 december 2003 amending Regulation 466/2001/EC as regards aflatoxins. Off. J. Eur. Commun. 2003, 326, 12.

99. Van Egmond, H.P.; Schothorst, R.C.; Jonker, M.A. Regulations relating to mycotoxins in food: Perspectives in a global and European context. J. Anal. Bioanal. Chem. 2007, 389, 147-157

100. WHO. Evaluation of certain food additives and contaminants. Thirty-seventh report of the joint FAO/WHO Expert Committee on Food Additives. WHO technical report series 806; World Health Organization: Geneva, Switzerland, 1991; pp. 29-31.

101. FAO. Biotechnology and food safety. Report of a Joint FAO/WHO consultation. Food and Agricultural Organization, Food and Nutrition, 1996.

102. FAO. Joint FAO/WHO Expert Committee on Food Additives, Fifty-sixth meeting, Geneva, Switzerland, 2001; pp. 6-15.

103. EC European Community. Opinion on of the Scientific Committee on Food (SCF) on Ochratoxin A, Luxembourg, 1998. Expressed on 17 September.

104. European Commission. Commission Regulation (EC) No 472/2002 of 12 March 2002. Off. J. Eur. Commun. 2002, 75, 18-20. 
105. European Commission. Commission Regulation (EC) No 466/2001 of 8 March 2001. Off. J. Eur. Commun. No. 2001, 77, 1-13.

106. European Commission. Commission Regulation (EC) No 123/2005 of 26 January 2005 amending Regulation (EC) No 466/2001 as regards ochratoxin A. Off. J. Eur. Commun. 2005, 25, 3-5.

107. Senyuva, H.Z.; Gilbert, J.; Ozcan, S.; Ulken, U. Survey of ochratoxin A and afaltoxin B1 in dried figs in Turkey using a single laboratory validated alkaline extraction method for ochratoxin A. J. Food Protect. 2005, 68, 1512-1515.

108. Levi, C.; Trenk, H.L.; Mohr, H.K. Study of the occurrence of ochratoxin A in green coffee beans. J. Assoc. Offic. Anal. Chem. 1974, 57, 866-870.

109. Nesheim, S.; Hardin, N.F.; Francis, O.I.; Langham, W.S. Analysis of ochratoxin A and B and their esters in barley: Using partitions and thin-layer chromatography. I Development of the method. J. AOAC Int. 1973, 56, 817-821.

110. El Adlouni, C.; Tozlovanu, M.; Naman, F.; Faid, M.; Pfohl-Leszkowicz, A. Preliminary data on the presence of mycotoxins (Ochratoxin A, citrinin and aflatoxin B1) in black table olives" Greek style" of Moroccan origin. Mol. Nutr. Food Res. 2006, 50, 507-512.

111. Mac Donald, S.; Wilson, P.; Barnes, K.; Damant, A.; Massey, R.; Mortby, E.; Shephered, M.J. Ochratoxin A in dried vine fruit: method development and survey. Food Addit Contam. 1999, 16, 253-260.

112. Legarda, T.M., Burdaspal, P.A. Ochratoxin A in beers brewed in Spain and other European countries. Alimentaria 1998, 291, 115-122.

113. NF EN 14133:2003. Food products. Determination of ochratoxin A in wine and beer - HPLC method with immunoaffinity column clean-up. Dansk Standard; Classification index V 03-128. IHS: Englewood, CO, USA, 2003.

114. Leoni, L.A.B.; Valente Soares, L.M.; Oliveira, P.L.C. Ochratoxin A in Brazilian roasted and instant coffees. Food Addit. Contam. 2000, 17, 10, 867-870.

115. Stegen, V.D.G.; Jorissen, U.; Pittet, A.; Saccon, M.; Steiner, W.; Vincenzi, M.; Winkler, M.; Zapp, J.; Schlatter, C. Screening of European coffee final products for occurrence of ochratoxin A (OTA). Food Addit. Contam. 1997, 14, 211-216.

116. Valenta, H.; Goll. M. Determination of ochratoxin A in regional samples of cow's milk from Germany. Food Addit. Contam. 1996, 13, 669-676.

117. Entwistle, C.A.; Williams, A.C.; Mann, P.J.; Russell, J.; Slack, P.; Gilbert, J. Combined phenyl silane and immunoaffinity column cleanup with liquid chromatography for determination of ochratoxin A in roasted coffee; Collaborative study. J. Assoc. Offic. Anal. Chem. Int. 2001, 84, $444-450$.

118. Gilbert, J.; Brereton, P.; MacDonald, S. Assessment of dietary exposure to ochratoxin A in the UK using a duplicate diet approach and analysis of urine and plasma samples. Food Addit. Contam. 2001, 18, 1088-1093. 
119. Entwistle, A.C.; Williams A.C.; Mann P.J.; Stack P.T.; Gilbert J. Liquid chromatographic method with immunoaffinity column clean up for determination of ochratoxin A in barley: Collaborative study. J. Assoc. Anal. Comm. 2000, 83, 1377-1383

120. Entwistle, A.C.; Williams, A.C.; Mann, P.J.; Russell, J.; Stack, P.T.; Gilbert, J. Combined phenyl silane and immunoaffinity column clean up with liquid chromatography for determination of ochratoxin A in roasted coffee: Collaborative study. J. Assoc. Anal. Comm. 2001, 84, 444-450.

121. Burdaspal, P.; Legarda, T.M.; Gilbert, J. Determination of ochratoxin A in baby food by immunoaffinity column cleanup with liquid chromatography: Interlaboratory study. J. Assoc. Offic. Anal. Chem. Int. 2001, 84, 1445-1452.

122. Dragacci, S.; Frémy, J.M. Dosage des mycotoxines. In Moisissures des aliments peuhydratés; Cahagnier, B., Ed.; Tec et Doc: Paris, France, 1998; pp. 187-207.

123. Wilson, D.M.; Sydenham, E.W.; Lombaert, G.A.; Trucksess, M.W.; Abramson, D.; Bennett, G.A. Mycotoxin analytical techniques. In Mycotoxins in Agriculture and Food Safety; Sinha, K.K., Bhatnagar, D., Eds.; Marcel Dekker, Inc.: New York, NY, USA, 1998.

124. Fukal, L.; Reisnerova, H. Monitoring of aflatoxins and ochratoxin A in Czechoslovak human sera by immunoassay. Bull. Environ. Contam. Toxicol. 1990, 44, 345-349.

125. Fukal, L.; Marek, M. A screening method for simultaneous immunochemical detection of aflatoxins and ochratoxin A in cereals and feed. Vet. Med. 1991, 36, 251-254

126. Rousseau, D.M.; Candlish, A.G.; Slegers, G.A.; Van Peteghem, C.H.; Stimson, W.H.; Smith, J.E. Detection of ochratoxin A in porcine kidneys by a monoclonal antibody-based radioimmunoassay. Appl. Environ. Microbiol. 1987, 53, 514-518.

127. Aizawa, M. Immunosensors. Philos. T. R. Soc. B 1987, 316, 121-134.

128. Niessen, L.; Schmidt, H.; Muhlencoert, E.; Farber, P.; Karolewiez, A., Geisen, P. Advances in the molecular diagnosis of ochratoxin A-producing fungi. Food Addit. Contam. 2005, 22, 324-334

129. Edwards, S.G.; O’Callaghan, J.; Dobson, A.D.W. PCR-based detection and quantification of mycotoxigenic fungi. Mycol. Res. 2002, 106, 1005-1025.

130. Moss, M.O. Recent studies of mycotoxins. Symp. Ser. Soc. Appl. Microbiol. 1998, 27, 62S-76S.

131. Proctor, R.H.; Desjardins, A.E.; Plattner, R.D.; Hohn, T.M. A polyketide synthase gene required for biosynthesis of fumonisin mycotoxins in Gibberella fujikuroi mating population A. Fungal Genet. Biol. 1999, 27, 100-112.

132. Bhatnagar, D.; Ehrlich, K.C.; Cleveland, T.E. Molecular genetic analysis and regulation of aflatoxin biosynthesis. Appl. Microbiol. Biotechnol. 2003, 61, 83-93.

133. Varga, J.; Kevei, E.; Rinyu, E.; Teren, J.; Kozakiewicz, Z. Ochratoxin production by Aspergillus species. Appl. Environ. Microbiol. 1996, 62, 4461-4464.

134. Huff, W.E.; Hamilton, P.B. Mycotoxins-their biosynthesis in fungi: Ochratoxins-metabolites of combined pathways. J. Food Prot. 1979, 42, 815-820. 
135. Schulz, B.; Sucker, J.; Aust, H.J.; Krohn, K.; Ludewig, K.; Jones, P.G. and Doring, D. Biologically active secondary metabolites of endophytic Pezicula species. Mycol. Res. 1995, 99, 1007-1015.

136. Venkatasubbaiah, P.; Sutton, T.B.; and Chilton, W.S. Effect of phytotoxins produced by Botryosphaeria obtusa, the cause of black rot of apple fruit and frogeye leaf spot. Physiol. Biochem. 1991, 81, 243-247.

137. Keller, B.; Winzeler, H.; Winzeler, M. and Fried, P.M. Differential sensitivity of wheat embryos against extracts containing toxins of Septoria nodorum: First Steps towards in vitro selection. J. Phytopathol. 1994, 141, 233-240.

138. Parisi, A.; Piattelli, M.; Tringali, C.; San Lio G.M.D.; Di San Lio, G.M. Identification of the phytotoxin mellein in culture fluids of Phoma tracheiphila; Phytochemistry: Oxford, UK, 1993; pp. 865-867.

139. Turner, W.B., Albridge, D.C. Fungal Metabolites; Academic Press Inc.: London, UK, 1983.

140. Camarda, L.; Merlini, L.; Nasini, G. Metabolites of Cercospora. Taiwapyrone, an $\alpha$-pyrone of unusual structure from Cercospora Taiwanensis. Phytochemistry 1976, 15, 537-539.

141. Assante, G.; Locci, R.; Camarda, L.; Merlini, L. and Nasini, G. Screening of the genus Cercospora for secondary metabolites. Phytochemistry 1977, 16, 243-247.

142. Claydon, N.; Grove, J.F.; Pople, M. Insecticidal secondary metabolic products from the entomogenous fungus Fusarium larvarum. J. Invert. Pathol. 1979, 33,364-367

143. Krohn, K.; Bahramsari, R.; Florke, U.; Ludewig, K.; Kliche-Spory, C.; Michel, A.; Aust, H.J.; Draeger, S.; Schulz, B.; Antus, S. Dihydroisocoumarins from fungi: Isolation, structure elucidation, circular dichroism and biological activity. Phytochemistry 1997, 45, 313-320.

144. Harris, J.P.; Mantle, P.G. Biosynthesis of diaporthin and orthosporin by Aspergillus ochraceus. Phytochemistry 2001, 57, 165-169.

145. Bingle, L.E.; Simpson, T.J.; Lazarus, C.M. Ketosynthase domain probes identify two subclasses of fungal polyketide synthase genes. Fungal Genet. Biol. 1999, 26, 209-223.

146. Liou, G.F.; Khosla, C. Building-block selectivity of polyketide synthases. Curr. Opin. Chem. Biol. 2003, 7, 1-6.

147. Nicholson, T.P.; Rudd, B.A.M.; Dawson, M.; Lazarus, C.M.; Simpson, T.J.; Cox, R.J. Design and utility of oligonucleotide gene probes for fungal polyketide synthases. Chem. Biol. 2001, 8, $157-178$.

148. O’Callaghan, J.; Caddick, M.X.; Dobson, A.D.W. A polyketide synthase gene required for ochratoxin A biosynthesis in Aspergillus ochraceus. Microbiology 2003, 149, 3485-3491.

149. Varga, J.; Rigó, K.; Kocsubé, S.; Farkas, B.; Pál, K. Diversity of polyketide synthase gene sequences in Aspergillus species. Res. Microbiol. 2003, 154, 593-600.

150. Atoui, A.; Dao., P.; Mathieu, F.; Lebrihi, A. Amplification and diversity analysis of Ketosynthase domains of putative polyketide synthase gene in Aspergillus ochraceus and Aspergillus carbonarius producers of ochratoxin A. Mol. Nutr. Food Res. 2006, 50, 448-493. 
151. Karolewiez, A.; Geisen, R. Cloning a part of the ochratoxin A biosynthetic gene cluster of Penicillium nordicum and characterisation of the ochratoxin polyketide synthase gene. Syst. Appl. Microbiol. 2005, 28, 588-595.

152. Bacha, N.; Atoui, A.; Mathieu, F.; Liboz, T.; Lebrihi A. Aspergillus westerdijkiae polyketide synthase gene "aoks1" is involved in the biosynthesis of ochratoxin A. Fungal Genet. Biol. 2009, 46, 77-84.

153. Sidhu, G.S. Mycotoxin genetics and gene clusters. Eur. J. Plant Pathol. 2002, 108, 705-711.

154. Yu, J.; Keller, N. Regulation of secondary metabolism in filamentous fungi. Annu. Rev. Phytopathol. 2005, 43, 437-458.

155. Brown, D.W.; Yu, J.H.; Kelkar, H.S.; Fernandes, M.; Nesbitt, T.C.; Keller, N.P.; Adams, T.H.; Leonard, T.J. Twenty-five coregulated transcripts define a sterigmatocystin gene cluster in Aspergillus nidulans. Proc. Natl. Acad. Sci. USA 1996, 93, 1418-1422.

156. Kato, N.; Brooks, W.; Calvo, A.M. The expression of sterigmatocystin and penicillin genes in Aspergillus nidulans is controlled by veA, a gene required for sexual development. Eukaryot. Cell 2003, 2, 1178-1186.

157. Yu, J.; Chang, P.K.; Ehrlich, K.C.; Cary, J.W.; Bhatnagar, D.; Cleveland, T.E.; Payne, G.A.; Linz, J.E.; Woloshuk, C.P.; Bennett, J.W. Clustered pathway genes in aflatoxin biosynthesis. Appl. Environ. Microbiol. 2004, 70, 1253-1262

158. O’Callaghan, J.; Stapleton, P.C; Dobson, A.D.W. Ochratoxin A biosynthetic genes in Aspergillus ochraceus are differentially regulated by $\mathrm{pH}$ and nutritional stimuli. Fungal Genet. Biol. 2006, 43, 213-221.

159. Yu, J.; Chang, P.-K.; Cary, J.W.; Bhatnagar, D.; Cleveland, T.E. avnA, a gene encoding a cytochrome P-450 monooxygenase, is involved in the conversion of averantin to averufin in aflatoxin biosynthesis in Aspergillus parasiticus. Appl. Environ. Microbiol. 1997, 63, 1349-1356.

160. Ward, T.J.; Bielawski, J.P.; Kistler, H.C.; Sullivan, E.; O’Donnell, K. Ancestral polymorphism and adaptive evolution in the trichothecene mycotoxin gene cluster of phytopathogenic Fusarium. Proc. Natl. Acad. Sci. USA 2002, 99, 9278-9283.

161. Ehrlich, K.C.; Chang, P.-K.; Yu, J.; Cotty, P.J. Aflatoxin biosynthesis cluster gene cypA is required for $\mathrm{G}$ aflatoxin formation. Appl. Environ. Microbiol. 2004, 70, 6518-6524.

162. Dao, H.P.; Mathieu, F.; Lebrihi, A. Two primer pairs to detect OTA producers by PCR method. Int. J. Food Microbiol. 2005, 104, 61-67.

163. Pel, H.J.W.; de Winde, J.H.; Archer, D.B.; Dyer, P.S.; Hofmann, G.; Schaap, P.J.; Turner, G.; de Vries, R.P.; Albang, R.; Albermann, K.; et al. Genome sequencing and analysis of the versatile cell factory Aspergillus niger CBS 513.88. Nat. Biotechnol. 2007, 25, 221-231.

164. Hendrickson, L.; Davis, C.R.; Roach, C.; Nguyen, D.K.; Aldrich, T.; Mcada, P.C.; Reeves, C.D. Lovastatin biosynthesis in Aspergillus terreus: characterization of blocked mutants, enzyme activities and a multifunctional polyketide synthase gene. J. Chem. Biol. 1999, 6, 429-439. 
165. Kennedy, J.; Auclair, K.; Kendrew, S.G.; Park, C.; Vederas, J.C.; Hutchinson, C.R. Modulation of polyketide synthase activity by accessory proteins during lovastatin biosynthesis. Science 1999, 284, 1368-1372.

166. Abe, Y.; Suzuki, T.; Ono, C.; Iwamoto, K.; Hosobuchi, M.; Yoshikawa, H. Molecular cloning and characterization of an ML-236B (compactin) biosynthetic gene cluster in Penicillium citrinum. Mol. Genet. Genom. 2002, 267, 636-646.

167. Kim, Y.T.; Lee, Y.R.; Jin, J.; Han, K.H.; Kim, H.; Kim, J.C.; Lee, T.; Yun, S.H.; Lee, Y.W. Two different polyketide synthase genes are required for synthesis of zearalenone in Gibberella zea. Mol. Microbiol. 2005, 58, 1102-1113.

168. Baker, S.E.; Kroken, S.; Asvarak, T.; Inderbitzin, P.; Li, B.Y.; Shi, L.; Yoder, O.C.; Turgeon, B.G. Two polyketide synthase-encoding genes are required for biosynthesis of the polyketide virulence factor, T-toxin, by Cochliobolus heterostrophus. Mol. Plant Microbe Interact. 2006, 19, 139-149.

169. Botton, A.; Ferrigo, D.; Scopel, C.; Causin, R.; Bonghi, C.; Ramina, A. A cDNA-AFLP approach to study ochratoxin A production in Aspergillus carbonarius. Int. J. Food Microbiol. 2008, 127, 105-115

170. Farber, P.; Geisen, R. Analysis of differentially expressed ochratoxin A biosynthesis genes of Penicillium nordicum. Eur. J. Plant Pathol. 2004, 110, 661-669.

171. Karolewiez, A.; Geisen R. Cloning a part of the OTA biosynthetic gene cluster of Penicillium nordicum and characterization of the ochratoxin polyketide synthase gene. Syst. Appl. Microbiol. 2005, 28, 588-595.

172. Farber, P.; Geisen, R.; Holzapfel, W.H. Detection of aflatoxigenic fungi in figs by a PCR reaction. Int. J. Food Microbiol. 1997, 36, 215-220.

173. Saiki, R.K.; Gelfand, D.H.; Stoffel, S.; Sharf, S.J.; Higuchi, R.; Horn, G.T.; Mullis, K.B.; Ehrlich, H.A. Primer-directed enzymatic amplification of DNA with a thermostable DNA polymerase. Science 1988, 239, 487-491.

174. Pelegrinelli-Fungaro M.H.; Vissoto P.C., Sartori, D., Vioas-Boas, L.A.; Furlaneto, M.C.; Taniwaki, M.H. A molecular method for detection of Aspergillus carbonarius in coffee beans. Curr. Microbiol. 2004, 49,123-127.

175. Schmidt H.; Ehrmann, M.; Vogel, R.F.; Taniwaki, M.H.; Niessen, L. Molecular typing of Aspergillus ochraceus and construction of species specific SCAR-primers based on AFLP. Syst. Appl. Microbiol. 2003, 26, 434-438.

176. Schmidt, H.; Bannier, M.; Vogel, R.F.; Niessen L. Detection and quantification of Aspergillus ochraceus in green coffee by PCR. Lett. Appl. Microbiol. 2004, 38, 464-469.

177. Schmidt, H.; Taniwaki, M.H.; Vogel, R.F.; Niessen, L. Utilization of AFLP markers for PCRbased identification of Aspergillus carbonarius and indication of its presence in green coffee samples. J. Appl. Microbiol. 2004, 97, 899-909. 
178. Vos, P.; Hogers, R.; Bleeker, M.; Reijans, M.; Van de Lee, T.; Hornes, M.; Frijters, A.; Pot, J.; Peleman, J.; Kuiper, M.; Zabeau, M. AFLP: A new technique for DNA fingerprinting. Nucl. Acids Res. 1995, 23, 4407-4414.

179. Castella, G.; Larsen, T.O.; Cabanes, F.J.; Schmidt, H.; Alboresi, A.; Niessen, L.; Farber, P.; Geisen, R. Molecular characterization of ochratoxin A producing strains of the genus Penicillium. Syst. Appl. Microbiol. 2002, 25, 74-83.

180. Perrone, G.; Susca, A.; Stea, G.; Mule, G. PCR assay for identification of Aspergillus carbonarius and Aspergillus japonicus. Eur. J. Plant Pathol. 2004, 110, 641-649.

181. Susca, A.; Stea, G.; Mule, G.; Perrone, G. Polymerase chain reaction (PCR) identification of Aspergillus niger and Aspergillus carbonarius based on the calmodulin gene. Food Addit. Contam. 2007, 24, 1154-1160

182. Mulè, G.; Susca, A.; Logrieco, A.; Stea, G.; Visconti, A. Development of a quantitative real-time PCR assay for the detection of Aspergillus carbonarius in grapes. Int. J. Food Microbiol. 2006, 111, 28-34.

183. Morello, L.G.; Sartori, D.; Martinez, A.L.O.; Carneiro Vieira, M.L.; Taniwaki, M.H.; Pelegrinelli Fungaro, M.H. Detection and quantification of Aspergillus westerdijkiae in coffee beans based on selective amplification of $\beta$-tubulin gene by using real-time PCR. Int. J. Food Microbiol. 2007, 119, 270-276

184. White, T.J.; Bruns, T.; Lee, S.; Taylor, J. Amplification and direct sequencing of fungi ribosomal RNA genes for phylogenetics. In PCR Protocols. A Guide to Methods and Applications; Innis, M.A., Gelfand, D.H., Sninsky, J.J., White, T.J., Eds.; Academic Press: San Diego, CA, USA, 1990; pp. 315-322.

185. Martínez-Culebras, P.V.; Ramón, D. An ITS-RFLP method to identify black Aspergillus isolates responsible for OTA contamination in grapes and wine. Int. J. Food Microbiol. 2007, 113, $147-153$.

186. Kappe, R.; Fauser, C.; Okeke, C.N.; Maiwald, M. Universal fungus-specific primer systems and group-specific hybridization oligonucleotides for 18 rDNA. Mycoses 1996, 39, 25-30.

187. Zhou, G.; Whong, W.Z.; Ong, T.; Chen, B. Development of a fungus-specific PCR assay for detecting low-level fungi in an indoor environment. Mol. Cell Probes 2000, 14, 339-348.

188. Vanittanakom, N.; Vanittanakom, P.; Hay, R.J. Rapid identification of Penicillium marneffei by PCR-based detection of specific sequences on the rRNA gene. J. Clin. Microbiol. 2002, 40, 1739-1742.

189. Hinukson, H.P.; Hurst, S.F.; Lott, T.J.; Warnock, D.N.; Morrison, C.J. Assessment of ribosomal large subunit D1-D2, ITS 1 and ITS 2 regions as targets for molecular identification of medically important Aspergillus species. J. Clin. Microbiol. 2005, 43, 2092-2103.

190. Gonzalez-Salgado, A.; Patno, B.; Vazquez, C.; Gonzalez-Jaen, M.T. Discrimination of Aspergillus niger and other Aspergillus species belonging to section Nigri by PCR assays. FEMS Microbiol. Lett. 2005, 245, 353-361 
191. Patino, B.; Gonzalez-Salgado, A.; Gonzalez-Jaen, M.T.; Vazquez, C. PCR detection assays for the ochratoxin-producing Aspergillus carbonarius and Aspergillus ochraceus species. Int. J. Food Microbiol. 2005, 104, 207-214.

192. Accensi, F.; Cano, J.; Figuera, L.; Abarca, M.L.; Cabanes, F.J. New PCR method to differentiate species in the Aspergillus niger aggregate. FEMS Microbiol. Lett. 1999, 180, 191-196.

193. Zanzotto, A.; Burruano, S.; Marciano, P. Digestion of DNA regions to discriminate ochratoxigenic and non-ochratoxigenic strains in the Aspergillus niger aggregate. Int. J. Food Microbiol. 2006, 110, 155-159

194. Niessen, L. Current trends in molecular diagnosis of ochratoxin A producing fungi. In Mycotechnology-Present Status and Future Prospects; Rai, M.; Ed.; I.K. International Publishing House: New Delhi, India, 2007; p. 320.

195. Shapira, R.; Paster, N.; Eyal, O.; Menasherov, M.; Mett, A.; Salomon, R. Detection of aflatoxingenic molds in grains by PCR. Appl. Environ. Microbiol. 1996, 62, 3270-3273.

196. Geisen, R. Multiplex polymerase chain reaction for the detection of potential aflatoxin and sterigmatocystin producing fungi. Syst. Appl. Microbiol. 1996, 19, 388-392.

197. Niessen, M.L.; Vogel, R.F. Specific identification of Fusarium graminearum by PCR with gaoA targeted primers. Syst. Appl. Microbiol. 1997, 20, 111-123.

198. Paterson, R.R.M. Identification and quantification of mycotoxigenic fungi by PCR. Process Biochem. 2006, 41, 1467-1474

199. Bluhm, B.H.; Flaherty, J.E.; Cousin, M.A.; Woloshuk, C.P. Multiplex polymerase chain reaction assay for the differential detection of trichothecene- and fumonisin-producing species of Fusarium in cornmeal. J. Food Prot. 2002, 65, 1955-1961.

200. Gonzalez-Jaen, M.T.; Mirete, S.; Patino, B.; Lopez-Errasquin, E.; Covadonga, V. Genetic markers for the analysis of variability and for production of specific diagnostic sequences in fumonisin-producing strains of Fusarium verticillioides. Eur. J. Plant Pathol. 2004, 110, 525-532.

201. Paterson, R.R.M. Primers from the isoepoxydon dehydrogenase gene of the patulin biosynthetic pathway to indicate critical control points for patulin contamination of apples. Food Control 2006, 17, 741-744.

202. Selma, M.V.; Martínez-Culebras, P.V.; Aznar, R. Real-time PCR based procedures for detection and quantification of Aspergillus carbonarius in wine grapes. Int. J. Food Microbiol. 2008, 122, 126-134

203. Atoui, A.; Mathieu, F.; Lebrihi, A. Targeting a polyketide synthase gene for Aspergillus carbonarius quantification and ochratoxin A assessment in grapes using real-time PCR. Int. J. Food Microbiol. 2007, 115, 313-318

204. Witter, C.T.; Herrmann, M.G.; Moss, A.A.; Rasmussen, A.P. Continuous fluorescence monitoring of rapid cycle DNA amplification. Biotechniques 1997, 22, 130-138. 
205. González-Salgado, A.; Patiño, B.; Gil-Serna, J.; Vázquez, C.; González-Jaén, M.T. Specific detection of Aspergillus carbonarius by SYBR ${ }^{\circledR}$ Green and TaqMan ${ }^{\circledR}$ quantitative PCR assays based on the multicopy ITS2 region of the rRNA gene. FEMS Microbiol. Lett. 2009, 295, 57-66.

206. Livak, K.J.; Flood, S.P.A.; Marmejo, J.; Giusti, W.; Deetz, K. Oligonucleotides with fluorescent dyes at opposite ends provide a quenched probe system useful for detecting PCR products and nucleic acid hybridization. PCR Met. Appl. 1995, 4, 357-362.

(C) 2010 by the authors; licensee Molecular Diversity Preservation International, Basel, Switzerland. This article is an open-access article distributed under the terms and conditions of the Creative Commons Attribution license (http://creativecommons.org/licenses/by/3.0/). 